\title{
Genes, Legitimacy and Hypergamy: Another look at the economics of marriage
}

\author{
Gilles Saint-Paul ${ }^{1}$ \\ Toulouse School of Economics and Birkbeck College
}

May 13, 2008

\footnotetext{
${ }^{1}$ I am grateful to seminar participants at Birkbeck College for helpful comments and suggestions.
} 


\begin{abstract}
In order to credibly "sell" legitimate children to their spouse, women must forego more attractive mating opportunities. This paper derives the implications of this observation for the pattern of matching in marriage markets, the dynamics of human capital accumulation, and the evolution of the gene pool. A key consequence of the trade-off faced by women is that marriage markets will naturally tend to be hypergamous - that is, a marriage is more likely to be beneficial to both parties relative to remaining single, the greater the man's human capital, and the lower the woman's human capital. As a consequence, it is shown that the equilibrium can only be of two types. In the "Victorian" type, all agents marry somebody of the same rank in the distribution of income. In the "Sex and the City" (SATC) type, women marry men who are better ranked than themselves. There is a mass of unmarried men at the bottom of the distribution of human capital, and a mass of single women at the top of that distribution. It is shown that the economy switches from a Victorian to an SATC equilibrium as inequality goes up.

The model sheds light on how marriage affects the returns to human capital for men and women. Absent marriage, these returns are larger for women than for men but the opposite may occur if marriage prevails. Finally, it is shown that the institution of marriage may or may not favour human capital accumulation depending on how genes affect one's productivity at accumulating human capital.
\end{abstract}

Keywords: Marriage markets, human capital accumulation, hypergamy, overlapping generations, legitimacy

JEL classification: D1, D13, D3, E24, I2, J12, J13, J16, K36, O15, O43, 


\section{Introduction}

This paper studies an economic model of marriage which is entirely based on the biological differences between men and women. The two most important differences are that, in nature, women know for sure whom their children are, while men don't; and that men can potentially have children with a large number of women, while women can't. ${ }^{1}$

Because of the first of these biological differences, there are gains from trade between men and women. Women can sell to men a guarantee that her children are his-a property I call legitimacy. Men are willing to pay for legitimacy because they can raise their utility by investing in their own children. This will hold provided men derive utility from quantity and quality of children ${ }^{2}$. This is true by assumption in this paper's model-in fact both men and women derive the same utility from consumption and children.

However, to provide such a guarantee, the woman must credibly commit to mate only with her husband. This implies that some long-term contract must be signed between a woman and a man, and that this contract must put penalties on female adultery - hence, the traditional marriage contract. ${ }^{3}$ Furthermore, the second biological difference between men and women implies that women have an opportunity cost of marrying. Instead of marrying, they could mate with men with the most desirable characteristics, and improve the genotype of their offsprings. Because these men's gametes are not

\footnotetext{
${ }^{1}$ There is a deep link between these two differences: female gametes are scarce because women provide the investment in natural resources to turn an embryo into a baby. This feature implies that they cannot produce a very large number of children and that they know for sure that they are theirs. The opposite is true for men.

${ }^{2}$ Although in the model higher human capital for the offspring does not enhance its survival probability, this is likely to be so in reality, which accounts why people value their children's human capital as a proxy for their own inclusive fitness.

${ }^{3}$ The model developed below aims at understanding marriage for most of human history; but in the last few decades contraception, IVF, (selective) abortion, and DNA testing have appeared. Clealry, these features decouple sexual intercourse from legitimacy. A new marriage contract may evolve. See Edlund (2005) for a thorough discussion.
} 
scarce, they have no cost of mating with as many women as possible, and they benefit from it to the extent that they derive utility from having illegitimate children. ${ }^{4}$ By marrying, a woman foregoes the superior genetic material of the most attractive men $^{5}$; on the other hand she benefits from the father's investment in the children's human capital and from increased consumption due to the public good aspect of children's human capital and from any implicit transfer from her husband. This trade-off will hold as long as men have different observable traits that are genetically heritable and valued by the parents in their children. In the model, it is assumed that children of more desirable men (the alpha men) are more productive in acquiring human capital.

This paper derives the implications of these observations for the pattern of matching in marriage markets, the dynamics of human capital accumulation, and the evolution of the gene pool. A key consequence of the trade-off faced by women is that marriage markets will naturally tend to be hypergamous - that is, a marriage is more likely to occur, the greater the man's human capital, and the lower the woman's human capital. The reason is that the utility loss from marrying a beta man instead of an alpha man is not transferable; therefore, the greater a woman's human capital, the lower her marginal utility of consumption, and the larger the transfer that she must get from a man in order to be compensated for her foregone mating opportunities. The opposite logic is at work for men: the larger their human capital, the lower their marginal utility of consumption, and the greater their willingness to pay for legitimate children.

At the end of this Introduction we discuss this paper's relationship to the existing literature. Then in Section 2 the model is set up, and we derive

\footnotetext{
${ }^{4}$ In the model, this is true; parents derive the same utility from their legitimate and illegitimate children. Because the latter are not known to the father, though, they cannot invest in their human capital, and, for this reason, do prefer to marry and have legitimate children.

${ }^{5}$ Unless she happens to marry a man with the highest genetic quality (an alpha in this paper's model), in which case marriage entails no opportunity cost to the woman. Nor would the alpha man have an opportunity cost under the double standard discussed further below in the paper.
} 
the equilibrium conditions for a "state of nature" where marriage does not exist, and for a society where marriage exists. We use a model of the intergenerational transmission of human capital with sexual reproduction, endogenous mating and household formation, and heritable genetic differences between people (alphas vs betas). People derive utility from consumption, and the quantity and quality of their children. Their income is proportional to their human capital, which depends on their genes and on their parent's investment. They allocate their income between their consumption and their children's human capital accumulation. A key result is that in the State of Nature, only the alpha men mate; the beta men are driven out of the market as they cannot credibly buy legitimacy from women. We then derive a condition for marriage to yield a positive surplus relative to each party remaining single is derived. This condition exhibits hypergamy: it is more likely to hold, the greater the man's human capital, and the smaller the woman's human capital.

Section 3 derives and discusses the model's prediction for the mating pattern. We characterize the equilibrium assignment of husbands to wife, and perform comparative statics with respect to this assignment. A perfectly competitive marriage market is assumed. It is shown that perfect assortative matching arises and that this is due to the public good aspect of the children in the woman's and the man's utility function. Because of the hypergamy effect, we can also show that the equilibrium can only be of two types. In the "Victorian" type, all agents marry somebody of the same rank in the distribution of income. In the model households produce the same number of boys and girls of each genetic type and provide the same investment in human capital to both; therefore, the distribution of human capital is the same for men and for women. In such a "Victorian" equilibrium, therefore, people marry somebody with exactly their human capital (homogamy). In the "Sex and the City" (SATC) type, women marry men who have more human capital than themselves. There is a mass of unmarried men at the bottom of the distribution of human capital, and a mass of single women at 
the top of that distribution. It is shown that the economy switches from a Victorian to an SATC equilibrium as inequality goes up; one interpretation is that less skilled women underbid more skilled ones for their husbands, which in equilibrium drives the skilled woman's share in bargaining down. As a result, the most skilled women end up better-off unmarried, and mating with alpha men. The same mechanism explains why the equilibrium may be SATC even though all homogamous marriages would be viable: starting from a homogamous assignment, less skilled women would successfully underbid more skilled ones by accepting a lower share of the surplus, thus driving them out of the marriage market. This suggests that perfect competition in marriage markets may reduce the number of marriages relative to other institutional arrangements for matching husbands and wives together. ${ }^{6}$

The model sheds light on how marriage affects the returns to human capital for men and women. In the State of Nature, these returns are larger for women than for men because they use their human capital both to invest in their children and to increase their own consumption. When marriage exists, this effect is equalized between men and women, but additional interesting effects arise. The returns to human capital depend on how the surplus is split between men and women at different levels of human capital: when inequality is large,competition for mates from low-skill women generates a downward profile of the woman's share in output as her human capital goes up. This tends to reduce the returns to human capital for women relative to men. Another effect arises if the equilibrium is SATC: a man has a lower quality spouse than a woman with the same level of human capital; therefore his marginal utility of consumption and his return to human capital are higher. Finally, in an SATC equilibrium, acquiring human capital may make a man eligible for marriage, while it may eliminate the benefits of marriage for a woman. This, too, tends to reduce the return to human capital for women relative to men. On the other hand, in an SATC equilibrium beta

\footnotetext{
${ }^{6}$ For example, in the case just discussed, there will be more marriages if instead of a competitive market, a social norm allocates a single partner of the same genetic type and human capital to each individual, thus replicating the Victorian assignment.
} 
men at the bottom of the distribution of skills are single and therefore have the same low return to human capital as in the State of Nature. Following this analysis, we may speculate that the decline of marriage may have something to do with men losing ground relative to women in higher education, relative to an initial situation where they did acquire more education than women ${ }^{7}$.

A consequence of the trade-off between father's investment and good genes is that marriage does not necessarily enhance the quality of children. It increases parental investment but more children are of the less productive "beta" type. Whether marriage is beneficial for human capital accumulation depends on the productivity difference between alpha and beta types, as well as on the elasticity of a child's human capital to parental investment. These aspects are discussed in Section 4. I first study whether a particular marriage improves the children's human capital relative to the mother remaining single and mating with an alpha male. I show that if the productivity difference between the two types is large, to benefit the children's human capital a marriage should be even more hypergamous than what is needed for its viability. These results clearly depend on the alphas being more productive rather than more sexually attractive instead. ${ }^{8}$ I then study whether the mating pattern is desirable from the point of view of the next generation's human capital level. In this model, as in many others in the literature, children cannot borrow to accumulate their own human capital and must stick with what they inherit from their parents. This creates an

\footnotetext{
${ }^{7}$ The assessment depends on how the decline of marriage is interpreted. As show below, a transition from a Victorian equilibrium to an SATC holding the distribution of human capital constant one increases the returns to human capital for married men because they are mated to women with less human capital than in the Victorian equilibrium. So the returns to human capital only fall for the men who end up single at the bottom of the skill distribution. On the other hand, a decline in marriage due to lower enforceability of monogamy and thus lower prospects for men to have legitimate children will uniformly move the economy closer to the State of Nature and unambiguously reduce the returns to human capital for men and increase them for women.

${ }^{8} \mathrm{~A}$ variant of the model can be constructed where the alphas are more sexually attractive but not more productive. The resulst regarding mating patterns would be unchanged but marriage would then unambiguously be good for human capital accumulation.
} 
intergenerational externality: investment in human capital does not maximize the utility of those in which it is embodied but that of their parents. Potentially, both the mating pattern and the investment level in human capital are different from the ones which would maximize the next generation's human capital. I characterize the assignment which maximizes the total human capital among children, and show that it involves negative assortative mating ("the Cinderella effect"). This is because such negative correlation between the wife's and the husband's human capital reduces inequality in household human capital, which is beneficial for the total human capital of the subsequent generation, due to decreasing returns in the technology of acquiring human capital. On the other hand, it remains true that if this allocation is such that there are some singles, these will be the least skilled men and the most skilled women, as their offspring's human capital is higher if they mate with an alpha man than if they get married. Finally, I move to a general equilibrium dynamic analysis and study (in the Victorian case) the long-run distribution of human capital and genes in the marriage economy and compares it to the state of nature, and derive conditions for average steady state human capital to be larger under marriage than under the state of nature. Again, this need not always hold and will not if the productivity difference between the two genotypes is large enough. Section 5 summarizes and concludes.

\subsection{Relationship to the existing literature}

This paper is related to the existing literature on marriage markets and on how this institution affects human capital accumulation. Overall, this literature has recognized that women are sellers in marriage markets either because of the sexual division of labor (Becker $(1973,1974)$ ) or because of the role played by women in reproduction (Aiyagari et al. (2000), Edlund (2006)). This paper's contribution is twofold. First, it brings back the abundance of male gametes and the existence of genetic differences in ability into the analysis, and accordingly identifies a trade-off for women as providers of 
legitimacy. Second, it fully analyses the consequences of that trade-off for the mating pattern and the evolution of the distribution of skills and genes.

The model described here fits with the general framework outlined by Becker $(1973,1974)$, but there are a number of substantial differences. In both models, households produce public goods and "own children" are the most important one (the only one we consider here). But while most of Becker's results rely on the sexual division of labor and the complementarities and substitutability between the tasks performed by husbands and wives, here, as discussed below, all the results come from the trade-offs between mate quality and father's investment that women face.

Another related paper is Aiyagari et al. (2000). As in Aiyagari et al., marriage generates an extra benefit to men in the form of utility derived from the human capital of their children, while women get this benefit regardless of whether they are married or not. Another common point is the use of the model to analyze the dynamics of human capital accumulation. A key difference, though, is that in their paper, marriage entails no per se opportunity cost for women, as there are no genetic differences in the population. As a result, hypergamy does not arise; also, they do not analytically solve for a marriage market equilibrium but instead rely on numerical simulations in the context of a matching model. ${ }^{9}$

Other papers that deal with various interactions between marriage markets and the transmission of human capital include Gould et al. (2004)

\footnotetext{
${ }^{9}$ There are many other differences between the two papers. Ayiagari et al. chiefly focus on marital dissolution and the role of the welfare state. This paper focuses on the consequences of hypergamy which arises from the women's trade-off between providing legitimacy and selecting a mate.

In their paper, contrary to this one, one has to be married to have children; single parents are divorced. Single fathers do not derive utility from their children's human capital by assumption; in the present model, a single divorced father would have incentives to invest in his children's human capital. Single men do not have that incentive here because they either have no children (if they are betas) or do not know their children (if they are alphas). In Aiyagari et al., women are assumed to have an intrinsic comparative advantage in child rearing: only the woman's input increases the child's human capital. In this model, there is perfect symmetry between the two sexes; the only asymmetry arises because of the relative abundance of male gametes which allows female to select the best possible mate according to their genetic characteristics.
} 
and Edlund and Lagerlof (2002). Gould et al. study the trade-off between polygamy and monogamy in a model where richer men can be married to more than one woman and therefore get more offspring. In their model, polygyny has adverse effects on aggregate human capital accumulation because each offspring gets a lower parental investment from the father. This situation is somewhat intermediate between monogamy and the nonmarriage state of nature (where the alpha men mate with several women) that are analyzed here. Edlund and Lagerlof (2004) compare "love" marriages where there is a transfer from husband to wife, to "arranged" marriages where the transfer goes to the bride's father. They argue that "love" marriages have better properties in terms of human and physical capital accumulation; the mechanism is quite different from the rest of the literature: parents do not care about their children's human capital per se but do care about their marriageability, and thus under "love marriage" want to transfer resources to their sons to increase their chances of mating.

Relative to this literature, the present paper focuses on the trade-off for women between providing legitimacy to a man by engaging in a monogamous marriage versus selecting a mate with more desirable characteristics. Here, all the differences between men and women are biological and derive from (i) the greater availability of man gametes and (ii) the impossibility for men to identify their own children absent an adequate institutional arrangement. In particular, none of the results rely on specialization and comparative advantage between the members of the household. Hypergamy arises because women, as sellers of legitimacy, face an opportunity cost for participating in marriage markets, regardless of how men and women are specialized in the production of home goods and market goods. By contrast, in Becker's model, a woman's income reduces her gain from marriage, while a man's income increases his gain from marriage, if the woman earns less than the man. The converse would occur should the woman earn more than the man. This is because household members specialize in tasks according to their comparative advantage and the gains from trade depend on their productivity difference 
regardless of sex. Hence, while Becker's model predicts that marriage rates should stop falling and increase again should women overtake men in relative economic status, the present model predicts that they will continue to decline.

Another key aspect of my analysis is that the desirable characteristics of the alpha men who would be available to women outside marriage are genetic and are inherited by the offspring. As a result, the model implies that the institution of marriage has an effect on the evolution of the gene pool. ${ }^{10} \mathrm{~A}$ consequence is that marriage does not necessarily enhance human capital accumulation. As in Gould et al. and Aiyagari et al., monogamous marriages increase parental investment by involving fathers into families. But here it has a downside, since marriage allows beta men to mate in addition to alpha men, thus increasing the proportion of less productive betas in the next generation. Consequently, for some parameter values the marriage market equilibrium has lower aggregate human capital accumulation than absent marriage.

In this paper, the marriage market equilibrium delivers assortative matching, as in a number of papers in the literature ${ }^{11}$. But the logic is a bit different. In Becker (1973), for example, the matching pattern is driven by complementarity and substitutability between the two members' contributions to the household public good. Here these contributions are perfect substitutes but sorting is affected by the overall economies of scales in a team's average human capital, as in Kremer (1993) and Saint-Paul (2001). The child's human capital is a public good and generates increasing returns that lead to positive assortative mating, despite the lack of complementarity between the man's and the woman's input. ${ }^{12}$

\footnotetext{
${ }^{10}$ Becker (1974) discusses the effect of marriage on natural selection from a very different perspective, focusing on the consequences of assortative mating.

${ }^{11}$ See for example Fernandez et al. (2001), Burdett and Coles (1997). In these models, as in Aiyagari et al., the marriage market is frictional. In Fernandez et al. and Aiyagari et al. people are entitled to two draws, while Burdett and Coles use a matching function framework. In contrast, here, we follow Becker (1973) and characterize a perfectly competitive assignment in marriage markets.

${ }^{12}$ This is in contrast to Becker's prediction, since his model predicts sorting with respect
} 


\section{The model}

\subsection{Basic setup}

At each generation, people are either male or female. They consume, produce offspring and invest in the human capital of their offspring. Generations are non-overlapping and people only live one period, as far as their economically relevant activities are concerned.

Utility. People care about their consumption and their children's human capital. I assume the same utility for men and women:

$$
U=\ln c+\gamma \sum_{i=1}^{n_{c}} E \ln h_{i}^{\prime},
$$

where $c$ is consumption, $n_{c}$ the number of children, $E$ the expectations operator, and $h_{i}^{\prime}$ the human capital of a child. People only care about the human capital of their true genetic offspring.

Genotypes. People differ in their genetic endowment. There are two genotypes: alpha $(\alpha)$ and beta $(\beta)$. One can make different assumptions about the role of genes, and they lead to different results. I will assume that the alphas have better genes in that it is easier for them to accumulate human capital. People then prefer alpha offsprings because these have a higher level of human capital for any given level of parental investment. Alternatively, though, one may assume that alpha people are more sexually attractive: mating with an alpha yields a utility gain but has no effect on the offspring's human capital. ${ }^{13}$ As long as the analysis is confined to the decision to marry and the assignment of husbands to wives, the two models are equivalent. But if mating with an alpha only yields direct utility gains then marriage

to other characteristics but not wages, where the comparative advantage logic prevails.

${ }^{13}$ This may be the case, for example, if the genetic advantage of the alphas evolved in a different environment with hunter-gatherer societies, in which the productivity advantage of the alphas was hard-wired in the form of greater attractiveness; the alphas would then have more appealing sexually but not be productive in the current environment. Note that if one were to assume that people care about their offsprings's attractiveness, rather than productivity, one could relabel attractiveness "human capital" and be back to model A (one would be in the special case where $\psi=0$ if parents cannot invest in attractiveness). 
unambiguously boosts the offspring's human capital, which is not necessarily true in the model studied below.

Production and human capital accumulation. The production structure is as follows: an individual with $h$ units of human capital can produce $A h$ of output. This output can be used either to consume or to invest in the children's human capital. For an isolated individual, therefore, the budget constraint is $c+n z=A h$, where $z$ is the per-child investment in human capital. ${ }^{14}$ The technology determining the offspring's human capital is then given by

$$
h^{\prime}=\alpha z^{\psi},
$$

if the child is an alpha, and

$$
h^{\prime}=\beta z^{\psi},
$$

if the child is a beta. We assume that $\alpha>\beta$ and that $0 \leq \psi \leq 1$. Thus, the alphas accumulate more human capital, for a given $z$, than the betas. Given that people care about their offspring's human capital, they would prefer to have alpha offsprings rather than beta offsprings.

For simplicity, I will also assume that people invest in their children's human capital before their type is observed.

Mating and children. People have access to unlimited possibilities of mating. All that is required is that both parties agree to mate. Mating produces offsprings. For simplicity, let's assume that each intercourse can produce one child. A woman (the sex with scarce gametes) can have up to $n$ children. In contrast, a man (the sex with abundant gametes) will have as many children as the number of intercourses he has had. We will restrict the analysis to a zone where the contribution of children to utility is always positive, so that each woman will indeed have $n$ children. We also assume that exactly $n / 2$ of them are girls and $n / 2$ are boys.

\footnotetext{
${ }^{14}$ I assume that all children get the same investment in human capital, which would be true in equilibrium given the concavity of utility in $h^{\prime}$ and given that the type of the child is not observed.
} 
The type of the child (alpha vs. beta) only depends on the type of his or her father. We assume that alpha fathers sire alpha children in proportion $p_{\alpha}$, while beta fathers sire beta children in proportion $p_{\beta}<p_{\alpha}$. That assumption implies that the mother's type has no effect on her children's type, and it is chiefly made for simplicity. The key mechanism of the model is that all women can get their offspring from some alpha male, as his gametes are infinitely abundant. The converse is not true; if alpha women increased the probability of having an alpha offspring, men would compete to mate with alpha women rather than beta women; presumably, there would be an implicit price or transfer that the former would get, but in equilibrium there would be men who cannot mate with alpha women and would have to settle with beta women, or not mate at all, instead. That is an interesting mechanism, which probably bears some relevance, but it is not my focus here. The key point is that no woman, either alpha or beta, has to settle for a beta man, because they can access the unscarce gametes of an alpha man instead.

\subsection{The State of Nature: No Marriage}

I now study the equilibrium in the "State of Nature", where individuals cannot contract on their mating behavior. I will consider the optimal behavior of men and women; starred variables refer to men's choices, and primed variables to the children.

In the state of nature, marriage does not exist. An important biological difference between men and women then kicks in: Men do not know who their offspring are. Consequently, they are not going to invest in the human capital of children. (More generally, though, they could discount the $\gamma n E \ln h^{\prime}$ term in their utility function by the probability that they are the actual father, which depends on parameters such as the size of the community they live in, how much of the private life of the women with whom they mated they have observed, and so on. The key point is that the incentives to invest in children are quite low compared to a marital society where men identify their own children with a much higher probability.) 
Because men do not observe who their children are, their consumption choice is simple: They will just set $c^{*}=A h^{*}$ and $z^{*}=0$. Their resulting utility is $\ln h^{*}+\ln A+\gamma \sum_{i=1}^{n^{*}} E \ln h_{i}^{\prime}$, where the latter part is determined by $n^{*}$, the number of intercourses, and $\left\{E \ln h_{i}^{\prime}\right\}$, the expected human capital of their children. They do not have any impact on that latter variable, which is determined by the woman. As for $n^{*}$, the man's utility is increasing with $n^{*}$ if and only if $E \ln h_{i}^{\prime}>0$. We will assume that parameter values are such that in equilibrium the distribution of human capital in the population is bounded from below: $h^{\prime}>1$. In such a case, utility is increasing in the number of children. Consequently, men's choices are simple: they accept all sexual intercourse and consume all their human capital endowment.

Since men accept all sexual intercourse, women can select which men they mate with. Since men do not provide resources to their children, the man's human capital is irrelevant to the woman's choice. Therefore, women will choose men on the basis of their genetic characteristics only. Since alpha children get more human capital for the same level of parental investment, women only mate with alpha men . Thus, $n^{*}=0$ for beta men, and $n^{*}=\frac{n}{\rho}$ for alpha men, where $\rho$ is the proportion of alpha men in the population. We can then rewrite their utility function as

$$
\bar{U}_{\beta}^{*}\left(h^{*}\right)=\ln A+\ln h^{*}
$$

for beta men, and

$$
\bar{U}_{\alpha}^{*}\left(h^{*}\right)=\ln A+\ln h^{*}+\sigma^{*},
$$

for alpha men, where $\sigma^{*}=\frac{\gamma n E \ln h^{\prime}}{\rho}$ is the hedonic value of their (unknown) children.

To allocate resources between consumption and investment in children, a woman maximizes

$$
\ln c+\gamma n\left(p_{\alpha} \ln \left(\alpha z^{\psi}\right)+\left(1-p_{\alpha}\right) \ln \left(\beta z^{\psi}\right)\right),
$$

subject to the budget constraint

$$
c+n z=A h .
$$


Note that, for simplicity, $z$ is the same across children since investment in children takes place before the child's genetic type is observed. In particular, since $n / 2$ of any woman's children are girls, the distribution of human capital will be the same, by construction, for men and women.

The solution to that problem is

$$
\begin{aligned}
z & =\frac{\gamma \psi}{1+\gamma n \psi} A h \\
c & =\frac{1}{1+\gamma n \psi} A h .
\end{aligned}
$$

The resulting utility is

$$
\bar{U}_{\alpha}(h)=(1+\gamma n \psi)(\ln A+\ln h)+\pi_{\alpha},
$$

where $\pi_{\alpha}$ is a constant representing the total hedonic value of having $n$ alpha children, which is given by

$$
\pi_{\alpha}=\gamma n\left(p_{\alpha} \ln \alpha+\left(1-p_{\alpha}\right) \ln \beta\right)+\gamma n \psi \ln (\gamma \psi)-(1+\gamma n \psi) \ln (1+\gamma n \psi) .
$$

Thus, women only mate with alpha men and invest a constant fraction of their resources into their children.

Note that if the man were beta, expected utility would instead be equal to

$$
\bar{U}_{\beta}(h)=(1+\gamma n \psi)(\ln A+\ln h)+\pi_{\beta},
$$

with

$$
\begin{aligned}
\pi_{\beta} & =\pi_{\alpha}-\gamma n\left(p_{\alpha}-p_{\beta}\right) \ln (\alpha / \beta) \\
& =\pi_{\alpha}-k,
\end{aligned}
$$

where

$$
k=\gamma n\left(p_{\alpha}-p_{\beta}\right) \ln (\alpha / \beta)
$$

is an index of the hedonic value to a woman of mating with an alpha man compared to a beta man, for a given level of parental investment. 
We will confine the analysis to situations where men and women are better-off having children on their own, even if the father is beta, rather than no children at all. That is - since the utility of a childless woman would also be given by $(1)$ - the values of $h$ are such that $\bar{U}_{\beta}(h)>\bar{U}_{\beta}^{*}(h)$, or equivalently

$$
h>h_{1}=A^{-1} e^{-\pi_{\beta} /(\gamma n \psi)} .
$$

The constant $h_{1}$ is the lowest level of a woman's human capital which makes it worthwhile to mate with a beta man and raise children on her own. Below that level, the children will inherit such a low level of skills that their contribution to the woman's utility will be negative.

\subsection{Marriage}

I now introduce marriage into the model. Marriage is a contract by which a woman commits to have intercourse with only one man-her husband. We are going to look at the individuals' willingness to sign such a contract, as opposed to remaining promiscuous and achieving an outcome similar to the state of nature described in the previous section.

The value of the marriage contract to a man, is that he knows his children are his, a property I will call legitimacy. Legitimacy makes it desirable for the man to increase his investment in the children's human capital. Both alpha men and beta men benefit from this. But the beta men benefit more. While the alpha men benefit from the fact that they know their children, the beta men benefit from the fact that marriage allows them to have children, which they cannot achieve in the state of nature.

What is the value of marriage for women? It mostly comes from the fact that there is a surplus from the match, due to children's human capital being a public good to the household. That surplus makes it possible for the man to transfer income to both his wife and his children, while remaining betteroff than if he were single. That, in turn, makes the wife better-off relative to being promiscuous. However, the surplus of the match differs considerably depending on whether the husband is alpha or beta. 
If the husband is alpha, the woman gets the same genetic quality for her children as if she were promiscuous. If the marriage contract is such that the alpha man has to be faithful, the man faces a trade-off between remaining promiscuous and potentially having more offsprings, versus marrying and having children of his own in whom he can invest. However, from a pure efficiency viewpoint, it is optimal for the couple to have a double standard by which the man can be promiscuous outside of the couple, while the woman cannot. The reason is that male promiscuity has no impact on the woman's knowledge that her children are hers. Furthermore, the illegitimate children are costless to the couple, as only their mothers invest in them. Thus, in this model, the surplus of the match is maximized if the alpha man is allowed to be promiscuous. In that section, I will therefore assume that this is the case, i.e. that the double standard holds ${ }^{15}$. Under the double standard, then, there is always a net positive surplus for a woman between a woman and an alpha male. The alpha man gets the same number of offsprings outside marriage as he would get should he be single, plus his legitimate children in whom he can invest. The woman gets the same genetic material as if she were single, plus the man's willingness to provide for his legitimate children.

If the husband is beta, the woman gets the man's willingness to provide for the children. But she gets a lower genetic material than if she were single and promiscuous, in which case she would have children with alpha men instead of a beta male. She needs to be compensated for that loss by the man transferring enough resources to her. As we shall see, that is possible only if the man has enough human capital both in the absolute and relative to the woman. Thus a marriage between a woman and a beta man yields a positive net surplus only if the man's human capital is high enough and if the woman's human capital is low enough. ${ }^{16}$

\footnotetext{
${ }^{15}$ The existence of a double standard in the treatment of adultery is widely documented throughout cultures. For example, Holmes (1995) shows that "The Divorce and Matrimonial Causes Act of 1857 included a double standard in its provisions. While a wife's adultery was sufficient cause to end a marriage, a woman could divorce her husband only if his adultery had been compounded by another matrimonial offence."

${ }^{16}$ Note that the double standard is not binding in that case since no promiscuous woman
} 
Let us now get into the analytics of this reasoning. We assume that when a man and a woman meet each other, they efficiently decide on whether to marry or not, and allocate consumption and investment in children efficiently within the household. The allocation will therefore maximize some weighted average of the two members' utilities: ${ }^{17}$

$$
\max \theta\left(\ln c+\gamma n E \ln h^{\prime}\right)+(1-\theta)\left(\ln c^{*}+\gamma n E \ln h^{\prime}+\sigma^{*}\right),
$$

where again $\sigma^{*}$ is the value to the man of children outside marriage ${ }^{18}$.

The budget constraint for the couple is now

$$
c+c^{*}+n z \leq A\left(h+h^{*}\right) .
$$

It can be seen that the optimal level of investment in children is

$$
z=\frac{\gamma \psi}{1+\gamma n \psi} A\left(h+h^{*}\right),
$$

which, conveniently, does not depend on $\theta$. The optimal allocation of consumption is then

$$
\begin{aligned}
c & =\frac{\theta}{1+\gamma n \psi} A\left(h+h^{*}\right) ; \\
c^{*} & =\frac{1-\theta}{1+\gamma n \psi} A\left(h+h^{*}\right) .
\end{aligned}
$$

The resulting utilities can be readily computed from the preceding derivations. Assuming a beta man, for the woman, we get

$$
U_{\beta}\left(h, h^{*}, \theta\right)=\ln \theta+(1+\gamma n \psi)\left(\ln A+\ln \left(h+h^{*}\right)\right)+\pi_{\beta},
$$

while the man's utility is given by

$$
U_{\beta}^{*}\left(h, h^{*}, \theta\right)=\ln (1-\theta)+(1+\gamma n \psi)\left(\ln A+\ln \left(h+h^{*}\right)\right)+\pi_{\beta} .
$$

wants to have intercourse with a beta male.

${ }^{17}$ The relevant weights $\theta$ and $1-\theta$ depend on the bargaining game played by the two parties, and on their outside option. The determination of $\theta$ is discussed in section 3.5.1.

${ }^{18}$ That is, for beta males, $\sigma^{*}=0$, and for alpha males, $\sigma^{*}=\frac{\gamma \bar{n}(1-m) E \ln h^{\prime}}{\rho}$, where $m$ is the equilibrium proportion of married women. Thus, the value of $\sigma^{*}$ that applies in a marital world is different from that in the State of Nature. 
The same formulae hold for a beta man, with $\pi_{\beta}$ replaced with $\pi_{\alpha}$.

Let us now analyze when marriage is beneficial relative to being single. A marriage is efficient provided there exists some $\theta$ such that each party can get a utility greater than their outside option. Let us briefly consider the case where the man is alpha. His utility outside marriage is given by $\bar{U}_{\alpha}^{*}\left(h^{*}\right)$ in (2). Outside marriage, his wife would get a utility $\bar{U}_{\alpha}(h)$ as given by (4). Inside marriage, since the children have the same distribution of genotypes as if the woman were single and mating with alpha men, that utility can be replicated by setting $c^{*}=A h^{*}, c=\frac{1}{1+\gamma n \psi} A h$ and $z=\frac{\gamma \psi}{1+\gamma n \psi} A h$. The couple can then improve on that by picking the optimal, higher level of human capital given by (6), and choosing the same consumption ratio between the two parties. Consequently, a match with an alpha man is always efficient, as long as the double standard allows the alpha man to remain promiscuous.

Now consider the case of a beta man. The woman's utility outside marriage is $\bar{U}_{\alpha}(h)$. Her utility inside marriage is $U_{\beta}\left(h, h^{*}, \theta\right)$. Confronting $(7)$ with (4), we see that for the woman to gain from marriage she must at least get a share $\theta_{\min }$ of consumption, where

$$
\theta_{\min }=e^{k}\left(1+\frac{h^{*}}{h}\right)^{-(1+\gamma n \psi)} .
$$

The match is efficient if the man's utility $U_{\beta}^{*}\left(h, h^{*}, \theta\right)$, computed at $\theta=$ $\theta_{\min }$, is greater than the man's outside option, which is given by $\ln A+\ln h^{*}$. That defines the condition under which the marriage takes place:

$$
1-\theta_{\min } \geq h_{1}^{\gamma n \psi} h^{*}\left(h+h^{*}\right)^{-(1+\gamma n \psi)} .
$$

Substituting the value of $\theta_{\min }$, we get the marriage viability condition:

$$
\left(h+h^{*}\right)^{1+\gamma n \psi} \geq h_{1}^{\gamma n \psi} h^{*}+e^{k} h^{1+\gamma n \psi} .
$$

This inequality defines the set of values of $\left(h, h^{*}\right)$ such that the match between a woman with human capital $h$ and a beta man with human capital $h^{*}$ is viable. 
Figure 1 depicts that set in the $\left(h^{*}, h\right)$ plane. We see that for any value of $h$, there exists a minimum value of $h^{*}$ such that the match is viable. Furthermore, that value is increasing with $h$. Therefore, there is hypergamy in that the match is more viable, the more skilled the man relative to the woman.

A woman with zero human capital is marriageable because an arbitrarily small consumption level is enough to compensate her for the opportunity cost of not mating with an alpha male, while her husband gets a finite benefit from legitimacy. As her human capital goes up, the consumption equivalent of foregone mating opportunities with alpha men goes up, and only men with a high enough level of human capital are willing to transfer that amount to her in exchange for legitimacy.

As Figure 1 shows, the marriageability frontier - the maximum human capital that the woman must have to marry a man with $h^{*}$ - converges from below to an asymptote, defined by

$$
h^{*}=h\left(e^{k /(1+\gamma n \psi)}-1\right)
$$

, when $h^{*}$ becomes large. That suggests that hypergamy is more stringent at low levels of human capital, in that the maximum $h / h^{*}$ ratio goes up with $h^{*}{ }^{19}$ This is because, due to the contribution of children to parent's utility, married men's utility is more elastic to their human capital than single men's utility. Therefore, men with large levels of human capital are willing to transfer virtually all their wealth in exchange for legitimate children, given their low marginal utility of consumption; poorer men are not willing to pay as much for legitimacy, which reduces the relative human capital of the women who are willing to settle with them.

\footnotetext{
${ }^{19}$ According to (9), mathematically, that maximum, given by $x$, is the largest root of $(1+x)^{1+\gamma \bar{n} \pi}-e^{k} x^{1+\gamma \bar{n} \psi}=\left(h_{1} / h^{*}\right)^{1+\gamma \bar{n} \psi}$.

That indeed defines a positive relationship between $h^{*}$ and $x$.
} 


\section{Who marries whom ? Marriage markets}

I now turn to the next question which is: who is going to marry whom? There are several alternative modelling choices that one may make. For example, one may assume that people meet once randomly and decide whether to marry or stay single. Or, the meeting may not be random and imply some correlation between the human capital and genetic endowment of the two mates. One can also consider more complex search decisions where mates can be turned down in the hope of a better mate. Here I assume that there is a perfect marriage market such that in the resulting assignment, it would not be profitable for an individual to outbid a mate from another couple. For simplicity, I am going to assume that alpha individuals and beta individuals cannot marry each other: there is a separate marriage market for each type. It is still possible, however for alpha and beta individuals to mate sexually and produce offsprings. Thus any single beta woman can get offsprings from an alpha man and the preceding analysis applies. In what follows, we focus on marriage patterns among the betas, and will return to the alphas later for the sake of completeness. All the analysis is performed for one generation only, taking as given their initial distribution of human capital, denoted by $f()$. The joint determination of $f()$ and the marriage market equilibrium will be discussed further in section 4.3.

\subsection{Defining an equilibrium}

The following definition clarifies the candidate equilibria. Note that it rules out equilibria where some individuals get married and other identical ones do not, except over a set of measure zero.

DEFINITION 1 - Let $f()$ be the distribution of human capital among the beta individuals, which is assumed to be the same between men and women. Let $\left[h_{\min }, h_{\max }\right]$ be the support of $f()$. An assignment is

(i) A pair of sets $S, S^{*} \subseteq\left[h_{\min }, h_{\max }\right]$ 
(ii) A mapping ${ }^{20} h^{*}()$ from $S$ to $S^{*}$

such that for any measurable set $\Sigma \subseteq S$

$$
\int_{\Sigma} f(h) d h=\int_{h^{*}(\Sigma)} f\left(h^{*}\right) d h^{*} .
$$

The sets $S, S^{*}$ tell us the set of women and men, respectively, who are married. The mapping $h^{*}()$ tells us whom marries whom. Condition (11) ensures that each woman marries exactly one man, so that for any set of women $\Sigma$ the measure of the set of their husbands is equal to the measure of $\Sigma$.

\footnotetext{
${ }^{20}$ If $h^{*}()$ is continuous, then to be a mapping it must be monotonic. But we do not actually require that it be continuous, so other configurations are possible. Note though that it is not the most general formulation, as it implies that each woman type marries exactly one man type, and vice versa. A more general formulation would introduce a measure of marriages over $\left[h_{\min }, h_{\max }\right]^{2}$.
} 
DEFINITION 2 - An assignment $\left(S, S^{*}, h^{*}()\right)$ is in equilibrium if there exists a function $\theta: S \rightarrow[0,1]$ such that:

(i) $\forall h \in S$,

$$
U_{\beta}\left(h, h^{*}(h), \theta(h)\right) \geq \bar{U}_{\alpha}(h)
$$

(ii) $\forall h \in S$,

$$
U_{\beta}^{*}\left(h, h^{*}(h), \theta(h)\right) \geq \bar{U}_{\beta}^{*}\left(h^{*}(h)\right)
$$

(iii) Let $V^{*}\left(h^{*}\right)=\bar{U}_{\beta}^{*}\left(h^{*}\right)$ if $h^{*} \notin S^{*}$ and $V^{*}\left(h^{*}\right)=U_{\beta}^{*}\left(h^{*-1}\left(h^{*}\right), h^{*}, \theta\left(h^{*-1}\left(h^{*}\right)\right)\right)$ if $h^{*} \in S^{*}$. Let $V(h)=\bar{U}_{\alpha}(h)$ if $h \notin S$ and $V(h)=U_{\beta}\left(h, h^{*}(h), \theta(h)\right)$ if $h \in S$.

For any $h, h^{*} \in\left[h_{\min }, h_{\max }\right]$, let $\hat{\theta}\left(h, h^{*}\right)$ be such that $U_{\beta}\left(h, h^{*}, \hat{\theta}^{*}\left(h, h^{*}\right)\right)=$ $V(h)$. Then the following must be true:

$$
\forall h, h^{*} \in\left[h_{\min }, h_{\max }\right], U_{\beta}^{*}\left(h, h^{*}, \hat{\theta}\left(h, h^{*}\right)\right) \leq V^{*}\left(h^{*}\right) .
$$

This definition spells out the three conditions for the equilibrium assignment to be better than any deviation. Condition (i) states that married women get a higher utility than if they were single. Condition (ii) states that married men get a higher utility than if they were single. Condition (iii) that no couple can be formed so that one party gets at least his/her reservation utility and the other gets strictly more than his/her reservation utility. $^{2122}$

\subsection{Properties of an equilibrium}

We now turn to analyzing the properties of the equilibrium assignment. A natural question to be asked is: will there be sorting? Intuitively, individuals

\footnotetext{
${ }^{21}$ For any $h, h^{*} \in\left[h_{\min }, h_{\max }\right]$ let $\hat{\theta}^{*}\left(h, h^{*}\right)$ be such that $U_{\beta}^{*}\left(h, h^{*}, \hat{\theta}^{*}\left(h, h^{*}\right)\right)=V^{*}\left(h^{*}\right)$. Then (14) is equivalent to:

$$
\forall h, h^{*} \in\left[h_{\min }, h_{\max }\right], U_{\beta}\left(h, h^{*}, \hat{\theta}^{*}\left(h, h^{*}\right)\right) \leq V(h) .
$$

To see this, just note that both conditions are equivalent to $\hat{\theta}^{*}\left(h, h^{*}\right) \leq \hat{\theta}\left(h, h^{*}\right)$.

${ }^{22}$ Note that this condition (14) holds with equality if the couple we consider is indeed married in equilibrium. Indeed, we can check that for $h^{*}=h^{*}(h), \hat{\theta}\left(h, h^{*}\right)=\hat{\theta}^{*}\left(h, h^{*}\right)=$ $\theta(h)$.
} 
with more human capital may be willing to pay more to get a higher quality mate. This is actually true here:

PROPOSITION 1 - Any equilibrium assignment function $h^{*}(h)$ must be nondecreasing.

PROOF - See Appendix.

This result comes from the public good aspect of children's human capital in the household. Absent children, people would be indifferent about whom they mate with and in equilibrium they would share resources within the household so as to replicate the singles' allocation of consumption. Marriage would then be a constant returns technology. Since, in addition to that, it provides benefits in the form of the children's human capital, it is an increasing returns technology: when the average human capital of a couple doubles, its output, in consumption-equivalent terms, more than doubles; not only can the consumption of each member double, but the quality of the children also goes up. For this reason, people with high human capital are willing to pay more to increase their spouse's human capital than people with low human capital; the usual sorting conditions hold.

In what follows, we will be able to elicit two types of equilibria, which we now define precisely.

DEFINITION 3 - An assignment is "Victorian" if $S=S^{*}=\left[h_{\min }, h_{\max }\right]$.

DEFINITION 4 - An assignment has the "Sex and the City" (SATC) property if there exists $\bar{h}<h_{\max }$ and $\underline{h}^{*}>h_{\min }$ such that $S=\left[h_{\min }, \bar{h}\right]$ and $S^{*}=\left[\underline{h}^{*}, h_{\max }\right]$.

A Victorian assignment is an assignment where everybody marries. Because $h()$ is nondecreasing, women must then marry men with the same rank in the distribution of income. Given that men and women have the same initial distribution of human capital, a Victorian assignment is homogamous, i.e. $h^{*}(h)=h .^{23}$

\footnotetext{
${ }^{23}$ Formally, denote by $\mu()$ the measure associated with $f()$ and by $F()$ the c.d.f. Then all people marry. For property (11) to hold, it must be that $\mu\left(\left[h_{\min }, h\right]\right)=\mu\left(\left[h_{\min }, h^{*}(h)\right]\right)$
} 
A "Sex and the City" assignment is such that any single woman has more human capital than any married woman, while the reverse holds for men. Because $h()$ is monotonous, an SATC assignment is hypergamous. Women must marry men who have a higher rank than them in the distribution of income: $h^{*}(h) \geq h^{24}$

If the assumption that men and women have the same distribution of human capital were relaxed, then these properties would still hold in terms of how the spouses are ranked in their own sex's distribution of human capital.

The following proposition shows that Victorian and SATC are the only two possible equilibrium types, provided $F()$ has full support.

PROPOSITION 2 - Assume F() has full support. Then the equilibrium assignment must be either Victorian or SATC.

PROOF - See Appendix.

Proposition 2 implies that in any equilibrium, the singles must be found at the top of the skilled distribution for women and at the bottom for the men. The mechanism behind this result is complex, as the reader can check by reading the proof. A first property is that if a man is better-off married than single, then all men with greater skills could also be better-off than single by marrying his wife and give her her reservation utility, which is associated with a smaller share of the now larger surplus than what she got with her original husband. This implies that $S^{*}=\left[\underline{h}^{*}, h_{\max }\right]$ for some $\underline{h}^{*}$. Another, less obvious, property is that there cannot be "holes" in $S$, i.e. $S$ must be an interval: single women who are richer than some married women and poorer than some other married ones can successfully underbid one of these two. Finally, the poorest married woman $(\underline{h})$ must marry the poorest married man $\left(\underline{h}^{*}\right)$. But if both of them are richer than $h_{\text {min }}$, competition from poorer

since, by monotonicity (Proposition 1$), h^{*}()$ maps $\left[h_{\min }, h\right]$ into $\left[h_{\min }, h^{*}(h)\right]$. That is equivalent to $F(h)=F\left(h^{*}(h)\right)$ for all $h$, i.e. $h^{*}(h)=h$. Similarly, in an SATC equilibrium, we must have $F(h)=F\left(h^{*}(h)\right)-F\left(\underline{h}^{*}\right)$, so that $h^{*}(h)>h$.

${ }^{24}$ If the distribution of human capital has full support and no mass point, this inequality holds strictly; if it is not degenerate in a single mass point, it holds strictly for some $h$. 
single men and women must drive the surplus of their match to zero-leaving them just as well off as if they were single. But this is not sufficient since a marriage between $\underline{h}^{*}$ and $h<\underline{h}$ would then generate a strictly positive surplus and therefore successfully break the original marriage. Therefore, there cannot be any single woman poorer than the poorest married one.

\subsection{Existence of Victorian equilibria}

Having established results regarding how any equilibrium looks like, we are now able to construct equilibria. In this section, I provide an existence result for Victorian equilibria. It should be noted that all homogamous marriages are viable, relative to both parties being single, if (9), which is more likely to hold at $h=h^{*}$ the greater their common value, holds for $h=h^{*}=h_{\min }$, or equivalently

$$
2^{1+\gamma n \psi} \geq h_{1}^{\gamma n \psi} h_{\min }^{-\gamma n \psi}+e^{k}
$$

One might speculate that if (15) holds, then the equilibrium is always Victorian, since all people are better-off in homogamous marriages than being single. However, that is not true: the condition for a Victorian equilibrium to exist is actually stronger than (15).

PROPOSITION 3 - Assume the following inequality holds:

$$
h_{\max }^{1+\gamma n \psi} \leq \frac{2^{\gamma n \psi} h_{\min }^{1+\gamma n \psi}-h_{1}^{\gamma n \psi} h_{\min }}{e^{k}-2^{\gamma n \psi}},
$$

then there exists a Victorian equilibrium assignment such that

(i) $S=S^{*}=\left[h_{\min }, h_{\max }\right]$

(ii) $h^{*}(h)=h$

(iii) $\theta(h)=\frac{1}{2}\left(1+\lambda h^{-(1+\gamma n \psi)}\right)$, where $\lambda$ is any number such that

$$
\begin{aligned}
& \max \left(\left(2^{-\gamma n \psi} e^{k}-1\right) h_{\max }^{1+\gamma n \psi},\left(2^{-\gamma n \psi} e^{k}-1\right) h_{\min }^{1+\gamma n \psi}\right) \\
\leq & \lambda \leq\left(1-2^{-\gamma n \psi} h_{1}^{\gamma n \psi} h_{\min }^{-\gamma n \psi}\right) h_{\min }^{1+\gamma n \psi}
\end{aligned}
$$

PROOF- See Appendix 
If (16) holds, then so does (15), but the converse is not true. Therefore, there are situations were homogamous mating would improve over being single for all people, yet we cannot construct it as an equilibrium. In fact we can show that (16) is not only sufficient, but necessary, for a Victorian equilibrium to exist:

PROPOSITION 4 - Assume (16) is violated. Then no Victorian equilibrium exists.

PROOF - See Appendix

\subsection{Existence of a "Sex and the City" equilibrium}

If (16) is violated, can we construct an SATC equilibrium? While I cannot prove existence of a marriage market equilibrium for any set of parameters (and I conjecture that for some parameters existence will fail), one can construct an SATC equilibrium if (16) is not violated by too much. This is what the next proposition says:

PROPOSITION 5 - Assume there exists $B>0$ such that if

$$
\frac{2^{\gamma n \psi} h_{\min }^{1+\gamma n \psi}-h_{1}^{\gamma n \psi} h_{\min }}{e^{k}-2^{\gamma n \psi}}<h_{\max }^{1+\gamma n \psi} \leq \frac{2^{\gamma n \psi} h_{\min }^{1+\gamma n \psi}-h_{1}^{\gamma n \psi} h_{\min }}{e^{k}-2^{\gamma n \psi}}+B
$$

then

(i) An SATC equilibrium exists such that $S=\left[h_{\min }, \bar{h}\right]$ and $S^{*}=\left[\underline{h}^{*}, h_{\max }\right]$

(ii) In this equilibrium, the assignment function is

$$
h^{*}(h)=F^{-1}\left(F(h)+F\left(\underline{h}^{*}\right)\right),
$$

implying $h^{*}\left(h_{\min }\right)=\underline{h}^{*}$. Furthermore, $\bar{h}=F^{-1}\left(1-F\left(\underline{h}^{*}\right)\right)$,implying $h^{*}(\bar{h})=$ $h_{\max }$.

(iii) The married woman's share in bargaining satisfies

$$
\theta(h)=\left(h+h^{*}(h)\right)^{-(1+\gamma n \psi)}\left[(1+\gamma n \psi) \int_{h_{\min }}^{h}\left(z+h^{*}(z)\right)^{\gamma n \psi} d z+\mu\right],
$$


where $\mu$ is a constant.

(iv) The equilibrium is locally unique

PROOF - See Appendix

Thus, singleness arises at the top of the skill distribution for women, and at the bottom for men, as an outcome of competition in marriage markets ${ }^{25}$. This, despite that the sex ratio is $1: 1$ and that (15) may hold ${ }^{26}$, i.e. that all homogamous marriages would be preferred to being single. ${ }^{27}$

\subsection{Discussion}

\subsubsection{How is output being shared?}

In both the SATC and the Victorian equilibrium, $\theta()$ satisfies the following differential equation:

$$
\theta^{\prime}(h)=\frac{1+\gamma n \psi}{h+h^{*}(h)}\left(\frac{1-\theta(h)}{\theta(h)}-h^{* \prime}(h)\right) .
$$

This equation is a first-order condition that tells us that locally, women with an arbitrarily close level of human capital cannot profitably underbid a married woman to get her husband (a similar condition for men leads to the same mathematical expression). The second term in parentheses, $h^{* \prime}(h)$, tells us that the larger the husband's human capital relative to the husbands of marginally less skilled woman, the lower the share of output that this woman can get, due to competition from these women. The first term tells us that the larger a woman's output share, the smaller (more negative) $\theta^{\prime}(h)$. This is because the greater her output share, the greater the incentives for marginally less skilled women to underbid her; for them to be deterred from doing that, their own output share must be higher, hence $\theta^{\prime}(h)$ must be lower.

\footnotetext{
${ }^{25}$ If (15) holds, any single woman could improve her lot by marrying a single man, provided he has at least as much human capital as she has. Therefore, any SATC equilbrium will be such that all single women have more human capital than all single men.

${ }^{26}$ In fact (15) always holds under the conditions of Proposition 5, since (16) is only violated marginally and it is stronger than (15).

${ }^{27}$ This stands in contrast to Edlund's (2005) analysis of the "Sex and the City phenomenon".
} 
While the sharing profile is determined in an SATC equilibrium, a Victorian one is compatible with a continuum of alternative sharing profiles, parametrized by the value of $\lambda$. If $e^{k} \leq 2^{\gamma n \psi}$, one may have $\theta(h)>1 / 2$ or $\theta(h)<1 / 2$. If $e^{k}>2^{\gamma n \psi}$, women necessarily get more than half the surplus.

The reason for this indeterminacy is that there are no singles. All couples are strictly better-off than if they were single, and a person's outside option in bargaining is determined by what he or she would get in another marriage. Therefore, the equilibrium assignment can be unchanged if one reallocates consumption between men and women while leaving these relative tradeoffs unchanged. Things are different in the SATC equilibrium where the sharing schedule must satisfy boundary conditions such that the most skilled married woman and the least skilled married man are indifferent between being married and single. An overall shift in the allocation of consumption which would leave the incentives for married people to underbid one another unaffected would violate these boundary conditions, so that the assignment could not be preserved.

\subsubsection{The role of inequality}

A key property of (16) is that it is more likely to be satisfied, the greater $h_{\min }$ and the lower $h_{\max }$. Therefore, greater inequality, as defined by a larger $h_{\max }$ and/or a lower $h_{\min }$ makes it more likely that the equilibrium, if any, be of the SATC type. In other words, inequality destroys the Victorian equilibrium and therefore has an averse effect on the number of marriages.

Let us try to provide some intuition for this result. The mechanism at work is an unraveling of marriage market competition throughout the distribution of income. If $e^{k} \leq 2^{\gamma n \psi}$, (16) always holds and the Victorian equilibrium always exists, regardless of $h_{\min }$ and $h_{\max }$. If $e^{k}>2^{\gamma n \psi}$, then Proposition 4 implies that $\lambda>0$, so that (i) women get more than $50 \%$ of the marriage's total consumption, and (ii) this share is lower, the greater the woman's human capital. Women get a large share of the surplus because $k$ is large, implying that the value of the lost genetic material from mating 
with a beta man instead of an alpha man is large. But this large share of the surplus has an effect on competition between married beta people: as implied by (21), the woman's output share must be more steeply decreasing with $h$. Hence, if $e^{k}>2^{\gamma n \psi}$, competition tends to reduce the share of highskill women and to increase that of low-skill women. But, if there is too much inequality, this process will be defeated by the exit options of low-skill men who will be better-off single than transferring a large share of the surplus to their wives. And similarly, high-skill women will get too low a share of the surplus for them to get appropriate compensation for mating with a beta man. This destroys the Victorian equilibrium and triggers a transition to an SATC equilibrium.

\subsubsection{The returns to human capital}

While the model has no role for the returns to human capital, since people cannot change the level of $h$ inherited from their parents, it is instructive to compute them among alternative arrangements. This is what we do below, comparing the marginal utility of human capital for men and women at a given level of human capital in the different situations we have analyzed.

State of Nature In the state of nature, women have a greater return on human capital than men:

$$
\begin{aligned}
\frac{d \bar{U}_{\beta}^{*}\left(h^{*}\right)}{d h^{*}} & =\frac{d \bar{U}_{\alpha}^{*}\left(h^{*}\right)}{d h^{*}}=\frac{1}{h^{*}} \\
\frac{d \bar{U}(h)}{d h} & =\frac{1+\gamma n \psi}{h} .
\end{aligned}
$$

This is because women invest their resources in both consumption and children, while men spend all on consumption. This suggest that if there were scope for accumulating human capital beyond what is inherited from parents, then in the state of nature women would acquire more human capital than men. 
Victorian equilibrium Let us now compute the rate of return to $h$ in the Victorian equilibrium. For beta women, it is equal to

$$
\begin{aligned}
\frac{d \bar{U}_{\beta}}{d h} & =\frac{\theta^{\prime}(h)}{\theta(h)}+\frac{1+\gamma n \psi}{h} \\
& =\frac{(1+\gamma n \psi)}{h+\lambda h^{-\gamma n \psi}}
\end{aligned}
$$

Similarly, for men we get

$$
\begin{aligned}
\frac{d \bar{U}_{\beta}^{*}}{d h^{*}} & =\frac{-\theta^{\prime}(h)}{1-\theta(h)}+\frac{1+\gamma n \psi}{h} \\
& =\frac{(1+\gamma n \psi)}{h-\lambda h^{-\gamma n \psi}} .
\end{aligned}
$$

If $\lambda>0$, i.e. $\theta(h)>1 / 2$, then men have a greater return to human capital than women. This is because by acquiring more human capital they end up marrying a woman with a smaller equilibrium share of output. The converse occurs for women. If $\lambda<0$, i.e. if $k$ is not too large, then the reverse holds: women have a greater return to human capital because in equilibrium their husband's output share falls as they climb the social ladder.

SATC equilibrium The analysis is richer in the case of an SATC equilibrium. For married women, the returns to human capital come from three components:

- The effect of their own human capital on the quality of their mate, which is equal to

$$
\frac{\partial U_{\beta}}{\partial h^{*}} h^{* \prime}(h)=\frac{(1+\gamma n \psi) h^{* \prime}(h)}{h+h^{*}(h)}
$$

The larger $h^{* \prime}(h)$, the greater the increase in the husband's human capital when the wife's human capital goes up by one unit. Since $h^{* \prime}(h)=\frac{f(h)}{f\left(h^{*}\right)}$ by virtue of $(19)$, this effect is stronger, the scarcer men are relative to women locally. 
- The effect of their human capital on their output share, given by

$$
\frac{\partial U_{\beta}}{\partial \theta} \theta^{\prime}(h)=\frac{\theta^{\prime}(h)}{\theta(h)}
$$

The return to human capital is greater, the greater the increment in the woman's output share when she climbs the social ladder. As implied by (21), this effect can be further decomposed into the effect of husband's incremental human capital and the effect of marriage competition. Straightforward computations show that the former exactly cancels the $\frac{\partial U_{\beta}}{\partial h^{*}} h^{* \prime}(h)$ term, so that $h^{* \prime}(h)$ disappears from the final formula.

- Finally, there is a direct effect due to the decreasing marginal utility of human capital; this effect is equal to

$$
\frac{\partial U_{\beta}}{\partial h}=\frac{1+n \gamma \psi}{h+h^{*}(h)}
$$

Similar effects hold for men. Putting all these effects together, we get the net return to human capital for women:

$$
V^{\prime}(h)=\frac{1+n \gamma \psi}{\theta(h)\left(h+h^{*}(h)\right)} .
$$

For men, the corresponding formula is

$$
V^{* \prime}\left(h^{*}\right)=\frac{1+n \gamma \psi}{\left(1-\theta\left(h^{*-1}\left(h^{*}\right)\right)\left(h^{*}+h^{*-1}\left(h^{*}\right)\right)\right.} .
$$

One effect tends to generate greater return to human capital for men than for women with the same skills: the former's mate has less skills than the latter's; because of hypergamy, total household human capital is smaller for men than for women with the same skills, hence the greater returns to skills for the former. This effect was not present in the homogamous Victorian equilibrium. The other effect is that of $\theta$, which is the same as in the Victorian equilibrium. If $\theta()>1 / 2$ then women will have a lower return to human capital because of the net effect of marriage competition. While we 
do not know in general whether this inequality holds, it does for the equilibria constructed in Proposition 5, because they are close to the limit Victorian equilibrium such that (16) holds exactly, and we know from Proposition 3 that $\lambda>0$, i.e. $\theta()>1 / 2$, for these equilibria.

\subsection{Comparative statics with respect to the assign- ment}

In this section, I provide further results on the comparative statics of the SATC assignment constructed in Proposition 5. The following result can be proved:

Proposition 6 - Under the conditions of Proposition 5, the following comparative statics result hold:

(i) $\frac{d h^{*}}{d k}>0 ; \frac{d \mu}{d k}>0$

(ii) $\frac{d \underline{h}^{*}}{d h_{1}}>0 ; \frac{d \mu}{d h_{1}}<0$

(iii) For a uniform distribution $F(), \frac{d \underline{h}^{*}}{d h_{\max }}>0, \frac{d \mu}{d h_{\max }}>0$ and the proportion of married people falls with $h_{\max }$.

PROOF-See Appendix.

This result tells us that the proportion of married people will fall, and the equilibrium gap in human capital between husbands and wives rise,

-if $k$ goes up, that is the opportunity cost of mating with a beta instead of an alpha goes up. This is natural, as an increase in $k$ raises the outside option of celibacy for the most skilled women. For the same reason, women get a higher share of output, i.e. $\mu$ goes up.

-if $h_{1}$ goes up, holding other parameters constant. The parameter $h_{1}$ is inversely related to the hedonic value of having children with a beta father, relative to not having children. The greater $h_{1}$, the lower the value of children. When $h_{1}$ goes up, the least skilled married men find themselves better-off being single, as their willingness to pay for children is lower. This will be the case if $A$ falls, since the marginal utility of consumption then goes up and makes it less valuable for men to give up income in exchange of legitimate 
children ${ }^{28}$. As a result, too, the women's share falls.

-if there is an increase in inequality due to a higher maximum level of human capital, in the case of a uniform distribution. Greater inequality reduces the proportion of women below $\bar{h}$, but increases the proportion of men above $\underline{h}^{*}$. This creates an imbalance in the marriage market, which leads to an increase in the women's share of output as well as an increase in $\underline{h}^{*}$. The total effect on the number of marriages is negative.

\section{The effect of marriage on the transmission of human capital.}

In this section I discuss the effect of the institution of marriage on the accumulation of human capital and the economy's growth path. I first analyze this question at the level of an individual couple: does marriage increase the human capital of their children relative to what they would get should their mother remain single. I then ask whether the equilibrium assignment is desirable from the point of view of the next generation's human capital. Finally, I provide some results regarding the effect of marriage on aggregate human capital accumulation.

\subsection{Partial equilibrium analysis}

One key aspect of marriage is that two parents, rather than one, now invest in the children's human capital. In the state of nature, parental investment is equal to $z=\frac{\gamma \psi}{1+\gamma n \psi} A h$; in the matrimonial society, it is equal to $z=$ $\frac{\gamma \psi}{1+\gamma n \psi} A\left(h+h^{*}\right)$. Because the child's human capital is a public good to his/her parents, establishing a link between fathers and their children works like a free lunch and makes all parties better-off. By introducing father's investment, one may increase the wife's consumption level while not reducing investment in the children.

\footnotetext{
${ }^{28}$ The other exogenous parameters that enter the definition of $h_{1}$ also appear elsewhere in the equilibrium equations. $A$ is the only parameter which acts through $h_{1}$ only.
} 
The free lunch occurs, however, only if we ignore that absent marriage the woman would have mated with an alpha male. For a couple where the man is alpha, that is inconsequential, and the children always get more human capital than if their mother remained single. Straightforward computations show that average offspring human capital is given by, in this case:

$$
\begin{aligned}
E \ln h_{M \alpha}^{\prime}= & \psi\left(\ln A+\ln \left(h+h^{*}\right)\right)+p_{\alpha} \ln \alpha+\left(1-p_{\alpha}\right) \ln \beta \\
& +\psi \ln (\gamma \psi)-\psi \ln (1+\gamma n \psi),
\end{aligned}
$$

while absent marriage it would be equal to

$$
\begin{aligned}
E \ln h_{S}^{\prime}= & \psi(\ln A+\ln h)+p_{\alpha} \ln \alpha+\left(1-p_{\alpha}\right) \ln \beta \\
& +\psi \ln (\gamma \psi)-\psi \ln (1+\gamma n \psi)
\end{aligned}
$$

For the couple where the man is beta, however, expected human capital is smaller than if the husband where alpha:

$$
\begin{aligned}
E \ln h_{M \beta}^{\prime}= & \psi\left(\ln A+\ln \left(h+h^{*}\right)\right)+p_{\beta} \ln \alpha+\left(1-p_{\beta}\right) \ln \beta \\
& +\psi \ln (\gamma \psi)-\psi \ln (1+\gamma n \psi) \\
= & E \ln h_{M \alpha}^{\prime}-\frac{k}{\gamma n} .
\end{aligned}
$$

We get that $E \ln h_{M \beta}^{\prime} \geq E \ln h_{S}^{\prime}$ if and only if

$$
h^{*} \geq h\left(e^{k /(\gamma n \psi)}-1\right) .
$$

That condition is not necessarily weaker than (9). In fact, it defines a lower $h / h^{*}$ ratio than the asymptote (10). That means that there are marriages that take place despite that they yield a lower human capital to the children than if the woman mated with an alpha man instead. The additional investment in children is not enough to compensate for the poorer genetic material. In such a situation, for the children to have more human capital in expectations, the husband should have even more human capital relative to the wife. Figure 2 illustrates this point by partitioning the plane in three zones: a zone where marriage does not take place, a zone where 
it takes place but children have lower quality than if their mother had not married and mated with an alpha man instead, and a zone where children have a higher quality than under that option.

Some marriages take place despite creating children of poorer average quality, because the mother gets a higher consumption level due to the "free lunch" aspect of legitimacy discussed above (while the father still gets the direct benefit of legitimacy). Marriage not only boosts investment in children but have consumption benefits as well.

An agent that would allocate marriages on the sole basis of children's human capital would implement a higher level of hypergamy than the party themselves. If, for example, the bride's parents can determine whom she marries, and if they care about their own consumption and about their grandchildren's quality, rather than their daughter's consumption, then they will reject applicants that their daughter would be happy to accept. This has been the theme of much popular literature, as exemplified by plays by Shakespeare, Molière, Goldoni, and others-although the model says nothing about why in these plays, the daughter wants to reject the richer applicants that their parents have chosen.

To summarize: While marriage always boosts investment in children, it does not necessarily boost their human capital, because of the implied reduction in the father's genetic quality. Human capital goes up if the marriage is sufficiently hypergamous or if the father is alpha. But it would always go up under the alternative assumption that alpha men are only more attractive and have no effect on the children's productivity.

\subsection{More results on the intergenerational externality}

By construction, the assignment studied in the preceding two sections is Pareto-optimal in that no alternative assignment allows to improve the utility of all agents in the generation of the parents. But the children have no say in the determination of their human capital, which is an intergenerational externality: parents value their own consumption in addition to their chil- 
dren's human capital, and typically choose a different investment level from what their children would do if they had access to perfect capital markets. This section studies the implications of that externality by performing two exercises. First, it asks how the results would be changed if children had access to financial markets that would allow them to choose their own level of human capital. We show that the results relative to the parent's assignments are qualitatively unchanged. Second, we ask how a "planner" who wants to maximize the total human capital of the children would choose the set of marriages. Such a planner will sometimes want all agents to marry, and sometimes want men with low human capital and women with high human capital to remain single. This is qualitatively similar to the equilibrium outcome. But whereas the equilibrium assignment has positive assortative mating, the planner's has negative assortative mating. We show that this "Cinderella effect" is due to decreasing returns in the production of human capital.

\subsubsection{The role of incomplete markets}

An important aspect of the model is that the market for human capital is incomplete. Individuals cannot borrow in order to purchase their own optimal investment in human capital $z$. Instead, they must inherit the level of investment decided by their parents.

What would happen if a market for human capital investment existed? To simplify, let us assume that people can also get insured against the risk of being a beta. Then people will choose their own $z$ by maximizing

$$
\max \frac{E h^{\prime}}{1+r}-z=\frac{\left(p_{\beta} \alpha+\left(1-p_{\beta}\right) \beta\right) z^{\psi}}{1+r}-z
$$

where $r$ is the relevant interest rate and the individual is assumed to have a beta father. The key point is that this optimization programme yields a constant value of $h^{\prime}$. All individuals with beta fathers will acquire the same level of human capital, denoted by $\bar{h}_{\beta}$, regardless of their parent's human capital. Similarly, children of alpha fathers will all have the same human 
capital $\bar{h}_{\alpha}>\bar{h}_{\beta}$.

How would this affect marriage markets? Clearly, as long as parents care about the human capital of their children, any parental investment would be inframarginal and not affect the child's optimal human capital. Hence, parents will no longer invest in their children's human capital. The utility of a woman married with a beta man is

$$
\ln \theta+\ln \left(A\left(h+h^{*}\right)\right)+\gamma n \ln \bar{h}_{\beta}
$$

her husband gets a utility equal to

$$
\ln (1-\theta)+\ln \left(A\left(h+h^{*}\right)\right)+\gamma n \ln \bar{h}_{\beta}
$$

A single beta man would get a utility equal to $\ln (A h)$, while a single woman would get a utility equal to $\ln (A h)+\gamma n \ln \bar{h}_{\alpha}$.

We see from these formulae that the analysis is the same as above in the special case where $\psi=0 .{ }^{29}$ The only novelty is that Proposition 1 no longer holds, because the sorting condition is satisfied with equality, so there may exist equilibria with a non-increasing assignment function. But we can still construct homogamous and SATC equilibria by applying propositions 4 and 6 with the required substitutions.

As in Galor and Zeira (1993), the lack of complete markets imply that children of poor households in equilibrium, have a higher marginal product of human capital than children of rich households. Consequently, inequality tends to reduce the total level of human capital among offsprings. This explains why a central planner who would maximize aggregate offspring human capital and could only affect the mating pattern would run against assortative matching and instead match high human capital women with low human capital men, and vice-versa (the Cinderella effect).

\footnotetext{
${ }^{29}$ The constants must also be redefined: $\pi_{\beta}$ and $\pi_{\alpha}$ are replaced by $\gamma n \ln \bar{h}_{\beta}$ and $\gamma n \ln \bar{h}_{\alpha}$, and $k$ by $\gamma n\left(\ln \bar{h}_{\alpha}-\ln \bar{h}_{\beta}\right)$.
} 


\subsubsection{Comparing the marriage market equilibrium assignment with the output maximizing assignment: the Cinderella effect.}

I now give formal content to this claim. Let us consider how a central planner would allocate husbands to wives among beta agents if he were maximizing the total human capital of offsprings. I will call the resulting assignment the "output-maximizing" solution.

First of all, a choice must be made about how human capital is aggregated among agents. A natural choice is to add it in logarithms, since it enters the utility function in logarithms and log human capital levels can easily be aggregated. But this builds a bias in favor of reducing the inequality in the distribution. Let us be more agnostic and maximize total human capital in levels.

Second, we must define the instruments available to the central planner. I will assume that he controls only the assignment function, and not the level of parental investment of each household, which is still determined by (8) and (3). I also assume (for simplicity and ease of comparison with the equilibrium) that the central planner cannot violate the "taboo" which prevents intermarriages between alphas and betas.

Equations (6) and (3) tells us that parental investment is proportional to the total human capital of the (legal) parents, with the same coefficient for single mothers and married couples. Therefore, the central planner maximizes

$$
\begin{aligned}
& \max _{h^{*}()} \int_{S}\left(p_{\beta} \alpha+\left(1-p_{\beta}\right) \beta\right)\left(h+h^{*}(h)\right)^{\psi} f(h) d h \\
& +\int_{\left[h_{\min }, h_{\max }\right]-S}\left(p_{\alpha} \alpha+\left(1-p_{\alpha}\right) \beta\right) h^{\psi} f(h) d h,
\end{aligned}
$$

and must pick the set of married women $S$ and the assignment function $h^{*}(h)$. The latter must be compatible with the supply of husbands, implying that the following constraint must be matched: 


$$
\forall S^{*} \subseteq S, \int_{S^{*}} f\left(h^{*}\right) d h^{*} \geq \int_{h^{*-1}\left(S^{*}\right)} f(h) d h .
$$

PROPOSITION 7 - The output maximizing solution must be such that

(i) All single women have more human capital than all married women

(ii) All single men have less human capital than all married men

(iii) The assignment function $h^{*}(h)$ is decreasing with $h$.

PROOF - See Appendix.

The reason why the output maximizing central planner prefers negative assortative mating is that there are decreasing returns to parental investment, and that in the absence of complete markets negative assortative mating allows to even the distribution of total parental human capital, which yields greater total output.

If some people remain single, then it must be the poorest men and the richest women. Clearly, if a married man were poorer than a single one, a swap between the two would increase parental investment in the offspring while having no effect on his or her genotype. Total output would then clearly go up. The property that single women are better skilled than married women comes from the fact that the output gain from marrying any given man is a decreasing function of the woman's human capital. This is due to two facts. First, there are decreasing returns to parental investment. Second, the output loss from getting beta children instead of alpha ones is larger, the larger total parental investment, i.e. the larger the mother's human capital.

Proposition 7 implies that the output maximizing solution can only be in three regimes, the next proposition characterizes these regimes.

PROPOSITION 8 - Let

$$
\kappa=\frac{p_{\alpha} \alpha+\left(1-p_{\alpha}\right) \beta}{p_{\beta} \alpha+\left(1-p_{\beta}\right) \beta}>1
$$

$$
\text { Let } \eta(h)=F^{-1}(1-F(h))
$$


(i) If

$$
\left(1+\frac{h_{\min }}{h_{\max }}\right)^{\psi} \geq \kappa,
$$

then the output maximizing solution is such that all agents get married; the corresponding assignment function is $h^{*}(h)=\eta(h)$.

(ii) If

$$
\left(1+\frac{h_{\min }}{h_{\max }}\right)^{\psi} \leq \kappa \leq\left(1+\frac{h_{\max }}{h_{\min }}\right)^{\psi},
$$

then the output maximizing solution is such that women are married for $h<\bar{h}$ and men are married for $h^{*}>\eta(\bar{h})$, where $\bar{h}$ is the unique solution to

$$
\left(1+\frac{\eta(\bar{h})}{\bar{h}}\right)^{\psi}=\kappa .
$$

The assignment function is $h^{*}(h)=\eta(h)$.

(iii) If

$$
\left(1+\frac{h_{\max }}{h_{\min }}\right)^{\psi} \leq \kappa,
$$

then the output maximizing solution is that nobody marries among the betas.

PROOF - See Appendix

This proposition is summarized in Figure 3 and tells us the following. For any level of inequality, as measured by $\frac{h_{\max }}{h_{\min }}$, the central planner's optimum can be in one of three regimes, depending on the productivity advantage of the alphas, as measured by $\kappa$. If it is large, then it is best to leave everybody single (No Marriage, NM). If it is small, then it is best to match each individual with his/her opposite in the other sex's distribution of income (The Cinderella-Victorian outcome, CV). Finally, for intermediate values of $\kappa$, the central planner wants the most skilled men to marry the least skilled women, again in a negative assortative matching fashion (The Cinderella-SATC outcome, CSATC). Furthermore, this regime is more likely, i.e. prevails for a wider range of values of $\kappa$, the greater the inequality. This makes sense since 
greater inequality makes it more likely that a marriage between the most skilled man and the least skilled woman improves their offspring's human capital relative to them remaining single, while the converse is true for a marriage between the most skilled woman and the least skilled man.

\subsection{The effect of marriage on aggregate human capital accumulation in the long-run}

I now study the effect of marriage on human capital accumulation in the economy as a whole, comparing human capital accumulation in the State of Nature with a marital economy in a Victorian equilibrium (computing aggregate capital accumulation in an SATC equilibrium proved analytically intractable).

\subsubsection{Aggregate human capital accumulation in the State of Na- ture}

A first step is to characterize aggregate human capital accumulation in the State of Nature. This is easy, provided average human capital is defined in logarithms. We get from (3):

$$
\begin{aligned}
E \ln h^{\prime} & =p_{\alpha} \ln \alpha+\left(1-p_{\alpha}\right) \ln \beta+\psi E \ln z \\
& =\psi E \ln h+v,
\end{aligned}
$$

where

$$
v=\psi \ln \left(\frac{\gamma \psi}{1+\gamma n \psi} A\right)+p_{\alpha} \ln \alpha+\left(1-p_{\alpha}\right) \ln \beta .
$$

Thus, average log human capital converges to $v /(1-\psi)$.

\subsubsection{Existence of a Victorian trajectory}

We now turn to the marital economy. An important technical step is to ensure that a marriage market equilibrium exists at all dates. To do so, we construct a Victorian equilibrium by checking that the inherited distribution of skills at each date satisfies the conditions of Proposition 3. A convenient 
feature is that the upper and lower bounds of the distribution of human capital among the alphas and the betas can be computed without knowing what this distribution actually is. Since only these bounds intervene in (16) we know that if it is satisfied then a Victorian equilibrium exists at all dates provided the initial distribution lies within these bounds. It is then straightforward to characterize the evolution of the economy's average human capital, as well as its genetic composition, and compare it to the state of nature.

$$
\begin{aligned}
& \text { PROPOSITION } 9-\text { Let } v_{1}=v+\left(1-p_{\alpha}\right) \ln \frac{\alpha}{\beta} . \text { Let } \\
& h_{\max , \alpha}^{L R}=\exp \left(\frac{v_{1}+\ln 2}{1-\psi}\right) ; \\
& h_{\max , \beta}^{L R}=\exp \left(\frac{v_{1}+\ln 2-(1-\psi) \ln \frac{\alpha}{\beta}}{1-\psi}\right) ; \\
& h_{\min , \beta}^{L R}=\exp \left(\frac{v_{1}+\ln 2-\ln \frac{\alpha}{\beta}}{1-\psi}\right) .
\end{aligned}
$$

Assume that the support of the initial distribution of human capital for alpha (resp. beta) people is contained in $\left[h_{\min , \beta}^{L R}, h_{\max , \alpha}^{L R}\right]$ (resp. $\left.\left[h_{\min , \beta}^{L R}, h_{\max , \beta}^{L R}\right]\right)$. Assume (16) holds at $h_{\max }=h_{\max , \beta}^{L R}$ and $h_{\min }=h_{\min , \beta}^{L R}$. Let $\rho_{t}$ be the proportion of alpha individuals. Then

(i) There exists a path for the economy where the marriage market equilibrium is Victorian for both the alphas and the betas at each date.

(ii) Along this path $\rho_{t}$ evolves according to

$$
\rho_{t+1}=p_{\beta}\left(1-\rho_{t}\right)+p_{\alpha} \rho_{t}
$$

(iii) The average log human capital of this economy, defined as $E \ln h_{t}$, evolves according to

$$
E \ln h_{t+1}=\psi E \ln h_{t}+v+\ln 2-\left(1-\rho_{t}\right)\left[p_{\alpha}-p_{\beta}\right] \ln \frac{\alpha}{\beta}
$$

PROOF - See Appendix. 
After having derived the conditions for a Victorian equilibrium to exist along a dynamic human capital accumulation path, which in some sense generalizes the results of section 3.3, we now discuss how marriage affects the economy's total human capital, which generalizes section 4 .

\subsubsection{Comparing Steady-State human capital with the State of Nature}

Comparing (27) with (25), it is easy to see that at date $t$, the society with marriage has more offspring human capital than the State of Nature iff $\ln 2-$ $\left(1-\rho_{t}\right)\left[p_{\alpha}-p_{\beta}\right] \ln \frac{\alpha}{\beta}>0$. In steady state, $(26)$ implies that $\rho=\frac{p_{\beta}}{1+p_{\beta}-p_{\alpha}}$. This equation is then equivalent to

$$
\ln 2>\left(p_{\alpha}-p_{\beta}\right) \frac{1-p_{\alpha}}{1-p_{\alpha}+p_{\beta}} \ln \frac{\alpha}{\beta} .
$$

This suggests that marriage boosts society's aggregate human capital if

(i) The alphas are not too different from the betas in terms of the likelihood of getting an alpha offspring, or

(ii) The alphas's productivity in accumulating human capital is not too different from the betas', or

(iii) The proportion of alphas is sufficiently large. ${ }^{30}$

A more stringent condition is for marriage to increase the human capital of the betas, relative to a situation where beta women mate with alpha men and remain single. The average human capital of the betas, denoted by $E \ln h_{t, \beta}$, evolves according to

$$
E \ln h_{t+1, \beta}=\psi E \ln h_{t, \beta}+v+\ln 2-\left[p_{\alpha}-p_{\beta}\right] \ln \frac{\alpha}{\beta}
$$

${ }^{30}$ The difference between the two long-run levels is then equal to

$$
\frac{\ln 2-\left(p_{\alpha}-p_{\beta}\right) \frac{1-p_{\alpha}}{1-p_{\alpha}+p_{\beta}} \ln \frac{\alpha}{\beta}}{1-\psi} .
$$

It is greater, the higher the proportion of alphas, the weaker the decreasing returns in the transmission of human capital, the lower the genetic loss from mating with a beta rather than an alpha 
Relative to the state of nature, beta offsprings get more human capital iff

$$
2>\left[p_{\alpha}-p_{\beta}\right] \ln \frac{\alpha}{\beta} .
$$

This is equivalent to

$$
e^{k} \leq 2^{\gamma n \psi}
$$

, i.e. to (24) for $h^{*}=h$. This is clearly more stringent than (16)-in particular, since $\omega(.,)>.2^{\gamma n \psi}$, the assumptions of Proposition 9 always hold if (28) holds. Therefore, if (28) holds, there exists a Victorian accumulation path and it improves over the State of Nature in terms of the beta's average human capital. But it may be that such a path exists while it reduces the beta's average human capital, although it will always increase the alpha's average human capital.

\section{Summary and conclusion}

By bringing fathers into the family, marriage allows to increase parental investment in children. But, for this to be credibly operational, monogamy must be enforced. As a result, women lose the opportunity of choosing more attractive mates.

Most of the results derive from this trade-off. Hypergamy arises from the fact that women must be compensated for the utility loss associated with the foregone mating opportunities. Assortative mating arises even though there are no complementarities between the skills of the two members of the couple, due to the public good aspect of children's human capital, which generates increasing returns to skills in the household.

The institution of marriage reduces the genetic quality of offspring, with that reduction being compensated by greater parental investment. As a result, a marital society does not necessarily imply greater human capital than the State of nature. As in Saint-Paul (2007), this is an example of institutions increasing the frequency of less fit genes as they provide alternative means of achieving fitness. But this result would be overturned if one holds the view 
that the mates with the best genes are not more productive but only more sexually attractive, in which case the marital society unambiguously achieves greater human capital.

Another key result is that inequality in skills in some sense intensifies competition in marriage markets and leads to "Sex and the City" equilibria where a pool of single women arises at the top, while a corresponding pool of single men emerges at the bottom of the distribution. 


\section{REFERENCES}

Aiyagari, S. Rao, Jeremy Greenwood and Nezih Guner (2000), "On the state of the union", Journal of Political Economy, 108(2), 213-244

Becker, Gary (1973), "A theory of marriage: Part I", Journal of Political Economy, 81(4), 813-846

(1974), "A theory of marriage: Part II", Journal of Political

\section{Economy}

Burdett, Kenneth and Melvyn Coles (1997), "Marriage and Class", Quarterly Journal of Economics, 112, 141-168

Edlund, Lena (2005), "Sex and the City", Scandinavian Journal of Economics, 107 (1), 25-44.

(2006), "Marriage: past, present, and future", CES-Ifo

Economic Studies

Edlund, Lena and Niles-Peter Lagerlof (2004), "Implications of marriage institutions for redistribution and growth", working paper, Columbia University

Fernandez, Raquel, Nezih Guner and John Knowles (2001), "Love and money: a theoretical and empirical analysis of household sorting and inequality", CEPR discussion paper \#3040

Galor, Oded and Joseph Zeira (1993), "Income Distribution and Macroeconomics", Review of Economic Studies Vol. 60, No. 1 (Jan., 1993), pp. $35-52$

Gould, Eric, Omer Moav and Avi Simhon (2004), "The mystery of monogamy", CEPR discusssion paper \#4803

Holmes, Ann Sumner, "The Double Standard in the English Divorce Laws, 1857-1923", Law \& Social Inquiry, 20, 2, 601-620

Saint-Paul, Gilles (2001), "On the distribution of income and worker assignment under intra-firm spillovers, with an application to ideas and networks", Journal of Political Economy

(2007), "On market forces and human evolution", Jour-

nal of Theoretical Biology 


\section{Appendix}

\subsection{Proof of Proposition 1}

Suppose it's not. Then we can find two married couples, $\left(h_{0}, h_{1}^{*}\right)$ and $\left(h_{1}, h_{0}^{*}\right)$, such that $h_{0}<h_{1}$ and $h_{0}^{*}=h^{*}\left(h_{1}\right)>h_{1}^{*}=h^{*}\left(h_{0}\right)$. Let $\theta_{0}=\theta\left(h_{0}\right)$ and $\theta_{1}=$ $\theta\left(h_{1}\right)$. For this assignment to be an equilibrium, condition (iv) in Proposition 2 must hold. Let us apply it for $h^{*}=h_{1}^{*}$ and $h=h_{1}$. Using (7) we see that

$$
\ln \hat{\theta}\left(h_{1}, h_{1}^{*}\right)=\ln \theta_{1}-(1+\gamma n \psi)\left(\ln \left(h_{1}+h_{1}^{*}\right)-\ln \left(h_{1}+h_{0}^{*}\right)\right) .
$$

Using (8) and (??), we see that we must have

$$
\ln \left(1-\hat{\theta}\left(h_{1}, h_{1}^{*}\right)\right) \leq \ln \left(1-\theta_{0}\right)+(1+\gamma n \psi)\left(\ln \left(h_{1}^{*}+h_{0}\right)-\ln \left(h_{1}^{*}+h_{1}\right)\right) .
$$

Substituting (29) we get that the following inequality must hold:

$$
\left(h_{1}+h_{1}^{*}\right)^{1+\gamma n \psi} \leq\left(1-\theta_{0}\right)\left(h_{1}^{*}+h_{0}\right)^{1+\gamma n \psi}+\theta_{1}\left(h_{1}+h_{0}^{*}\right)^{1+\gamma n \psi}
$$

If we now apply condition (iv) to $h^{*}=h_{0}^{*}$ and $h=h_{0}$, we get a similar condition

$$
\left(h_{0}+h_{0}^{*}\right)^{1+\gamma n \psi} \leq\left(1-\theta_{1}\right)\left(h_{1}+h_{0}^{*}\right)^{1+\gamma n \psi}+\theta_{0}\left(h_{1}^{*}+h_{0}\right)^{1+\gamma n \psi} .
$$

Adding these two inequalities, we get that the following must hold

$$
\left(h_{1}+h_{1}^{*}\right)^{1+\gamma n \psi}+\left(h_{0}+h_{0}^{*}\right)^{1+\gamma n \psi} \leq\left(h_{1}+h_{0}^{*}\right)^{1+\gamma n \psi}+\left(h_{1}^{*}+h_{0}\right)^{1+\gamma n \psi} .
$$

However, the strict convexity of the function $\psi(x)=x^{1+\gamma n \psi}$ precludes it. Let $\mu=\frac{h_{1}-h_{0}}{h_{1}-h_{0}+h_{1}^{*}-h_{0}^{*}} \in[0,1]$. One has $h_{1}+h_{0}^{*}=\mu\left(h_{1}+h_{1}^{*}\right)+(1-\mu)\left(h_{0}+h_{0}^{*}\right)$, and $h_{1}^{*}+h_{0}=(1-\mu)\left(h_{1}+h_{1}^{*}\right)+\mu\left(h_{0}+h_{0}^{*}\right)$. Therefore, $\psi\left(h_{1}^{*}+h_{0}\right)<$ $(1-\mu) \psi\left(h_{1}+h_{1}^{*}\right)+\mu \psi\left(h_{0}+h_{0}^{*}\right)$ and $\psi\left(h_{1}+h_{0}^{*}\right)<\mu \psi\left(h_{1}+h_{1}^{*}\right)+(1-\mu) \psi\left(h_{0}+h_{0}^{*}\right)$. Adding these two inequalities, we clearly contradict (30). QED 


\subsection{Proof of Proposition 2}

The first step is to show that if a man is married, all men with greater human capital must also be married. To see this, consider a single man with human capital $h_{0}^{*}$, married with a woman with human capital $h_{0}$. Let $\theta_{0}=\theta\left(h_{0}\right)$ her corresponding equilibrium output share. A man with human capital $h_{2}^{*}>h_{0}^{*}$ can marry her if he gives her a share $\hat{\theta}\left(h_{0}, h_{2}^{*}\right)$ such that $U_{\beta}\left(h_{0}, h_{2}^{*}, \hat{\theta}\left(h_{0}, h_{2}^{*}\right)\right)=V\left(h_{0}\right)=U_{\beta}\left(h_{0}, h_{0}^{*}, \theta_{0}\right)$, or equivalently, using $(7)$,

$$
\ln \hat{\theta}\left(h_{0}, h_{2}^{*}\right)=\ln \theta_{0}+(1+\gamma n \psi)\left[\ln \left(h_{0}+h_{0}^{*}\right)-\ln \left(h_{0}+h_{2}^{*}\right)\right] .
$$

If $h_{2}^{*}$ is single, then he must not be better-off by marrying $h_{0}$ and offering her an output share equal to $\hat{\theta}\left(h_{0}, h_{2}^{*}\right)$; otherwise, (14) would be violated. Therefore, we must have $U_{\beta}^{*}\left(h_{0}, h_{2}^{*}, \hat{\theta}\left(h_{0}, h_{2}^{*}\right)\right) \leq V\left(h_{2}^{*}\right)=\bar{U}_{\beta}^{*}\left(h_{2}^{*}\right)$, or equivalently, using (8) and (1),

$$
\ln \left(1-\hat{\theta}\left(h_{0}, h_{2}^{*}\right)\right) \leq \gamma n \psi \ln h_{1}+\ln h_{2}^{*}-(1+\gamma n \psi) \ln \left(h_{0}+h_{2}^{*}\right) .
$$

Substituting (31) into (32), we see that the following inequality must hold:

$$
\left(h_{0}+h_{2}^{*}\right)^{1+\gamma n \psi}-\theta_{0}\left(h_{0}+h_{0}^{*}\right)^{1+\gamma n \psi} \leq h_{1}^{\gamma n \psi} h_{2}^{*} .
$$

At the same time, $h_{0}^{*}$ must be better-off married with $h_{0}$ than single, otherwise (13) would be violated. Using (8) and (1), this is equivalent to

$$
\left(h_{0}+h_{0}^{*}\right)^{1+\gamma n \psi}-\theta_{0}\left(h_{0}+h_{0}^{*}\right)^{1+\gamma n \psi} \geq h_{1}^{\gamma n \psi} h_{0}^{*} .
$$

Putting together (34) and (33), we see that the following inequality must hold:

$$
\left(h_{0}+h_{0}^{*}\right)^{1+\gamma n \psi}-h_{1}^{\gamma n \psi} h_{0}^{*} \geq\left(h_{0}+h_{2}^{*}\right)^{1+\gamma n \psi}-h_{1}^{\gamma n \psi} h_{2}^{*} .
$$

But, since $h_{\min }>h_{1}$, the expression $\left(h_{0}+x\right)^{1+\gamma n \psi}-h_{1}^{\gamma n \psi} x$ is strictly increasing in $x$, and therefore (35) cannot hold for $h_{2}^{*}>h_{0}^{*}$. Therefore, $h_{2}^{*}$ must be married too. Consequently, it must be that $S^{*}=\left[\underline{h}^{*}, h_{\max }\right]$. 
Next, we show that the inverse assignment function $h^{*-1}()$ must be continuous over $S^{*}$. Suppose it is not the case. Since it is monotonic, the set of its discontinuity points is at most countable. Then there exists some $h_{0}^{*} \in \stackrel{\circ}{S}$ such that $h_{2}=\lim _{h^{*} \rightarrow h_{0}^{*+}} h^{*-1}()>h^{*-1}\left(h_{0}^{*}\right)=h_{0} \cdot{ }^{31}$ Then, all women in $\left(h_{0}, h_{2}\right)$ must be single. Furthermore, a man with human capital $h_{0}^{*}$ must be indifferent between marrying a woman with human capital $h_{0}$ or a woman with human capital (arbitrarily close to) $h_{2}$. Denoting $\theta_{0}=\theta\left(h_{0}\right)$ and $\theta_{2}=\lim _{h \rightarrow h_{2}^{+}} \theta(h)$, this can be written as

$$
\ln \left(1-\theta_{2}\right)+(1+\gamma n \psi) \ln \left(h_{0}^{*}+h_{2}\right)=\ln \left(1-\theta_{0}\right)+(1+\gamma n \psi) \ln \left(h_{0}^{*}+h_{0}\right)
$$

Another equilibrium condition is that all women such that $h \in\left(h_{0}, h_{2}\right)$ could not be better-off if they married $h_{0}^{*}$. The woman's output share that would leave him indifferent between marrying $h_{0}$ or $h_{2}$ and marrying $h$ is $\hat{\theta}^{*}\left(h, h_{0}^{*}\right)$ such that

$$
\ln \left(1-\hat{\theta}^{*}\left(h, h_{0}^{*}\right)\right)=(1+\gamma n \psi) \ln \left(h_{0}^{*}+h_{0}\right)+\ln \left(1-\theta_{0}\right)-(1+\gamma n \psi) \ln \left(h_{0}^{*}+h\right) .
$$

That a woman with $h \in\left(h_{0}, h_{2}\right)$ prefers to be single than marrying $h_{0}^{*}$ under these terms can be written as

$$
k+(1+\gamma n \psi) \ln h \geq \ln \hat{\theta}^{*}\left(h, h_{0}^{*}\right)+(1+\gamma n \psi) \ln \left(h_{0}^{*}+h\right) .
$$

Note that $\hat{\theta}^{*}\left(h_{0}, h_{0}^{*}\right)=\theta_{0}$ and $\hat{\theta}^{*}\left(h_{2}, h_{0}^{*}\right)=\theta_{2}$. Taking limits in (38) for $h \rightarrow h_{0}$ and $h \rightarrow h_{2}$ and noting that a woman with $h=h_{0}$ or $h$ arbitrarily close to $h_{2}$ is married in equilibrium and thus not worse-off than single, we see that (38) must hold with equality at the bounds of $\left(h_{0}, h_{2}\right)$, i.e.

$$
\begin{aligned}
& k+(1+\gamma n \psi) \ln h_{0}=\ln \theta_{0}+(1+\gamma n \psi) \ln \left(h_{0}^{*}+h_{0}\right) ; \\
& k+(1+\gamma n \psi) \ln h_{2}=\ln \theta_{2}+(1+\gamma n \psi) \ln \left(h_{0}^{*}+h_{2}\right) .
\end{aligned}
$$

\footnotetext{
${ }^{31}$ Here we assume the discontinuity takes place on the right of $h_{0}^{*}$. Nothing would change in the argument if it were on the left.
} 
Using (39) and (40) to eliminate $\theta_{0}$ and $\theta_{2}$ in (36), we get that

$$
\left(h_{0}^{*}+h_{2}\right)^{1+\gamma n \psi}-e^{k} h_{2}^{1+\gamma n \psi}=\left(h_{0}^{*}+h_{0}\right)^{1+\gamma n \psi}-e^{k} h_{0}^{1+\gamma n \psi} .
$$

Let $\phi(h)$ be the function defined by $\phi(h)=\left(h_{0}^{*}+h\right)^{1+\gamma n \psi}-e^{k} h^{1+\gamma n \psi}$. It is easy to see that $\phi^{\prime}(h)$ is positive and then negative as $h$ goes from zero to infinity. Since $\phi\left(h_{0}\right)=\phi\left(h_{2}\right), \phi()$ must be hump-shaped between $h_{0}$ and $h_{2}$, implying that

$$
\phi(h)>\phi\left(h_{0}\right)=\phi\left(h_{2}\right) \text { for } h \in\left(h_{1}, h_{2}\right) .
$$

But, substituting (37) into (38), we see that we must also have

$$
\left(h+h_{0}^{*}\right)^{1+\gamma n \psi}-e^{k} h^{1+\gamma n \psi} \leq\left(1-\theta_{0}\right)\left(h_{0}^{*}+h_{0}\right)^{1+\gamma n \psi} .
$$

Substituting again the value of $\theta_{0}$ from (39), we see that this is equivalent to

$$
\left(h+h_{0}^{*}\right)^{1+\gamma n \psi}-e^{k} h^{1+\gamma n \psi}=\phi(h) \leq \phi\left(h_{0}\right)=\left(h_{0}+h_{0}^{*}\right)^{1+\gamma n \psi}-e^{k} h_{0}^{1+\gamma n \psi},
$$

which is clearly a contradiction. Therefore, the inverse assignment function must be continuous, implying that $S$ is an interval.

Let $\underline{h}$ be the lower bound of $S$. It must be that $h^{*}(\underline{h})=\underline{h}^{*}$. If $\underline{h}^{*}=$ $h_{\min }$, then all men are married, so must all women, and one must have $S=$ $\left[h_{\min }, h_{\max }\right]$. The equilibrium is then Victorian. Assume then that $\underline{h}^{*}>h_{\min }$. Assume $\underline{h}>h_{\min }$. Then, all women such that $h<\underline{h}$ are single. We can use similar steps as the ones used to derive (37)-(40) to show that $\underline{h}$ is just indifferent between being married and single, i.e.

$$
k+(1+\gamma n \psi) \ln \underline{h}=\ln \theta(\underline{h})+(1+\gamma n \psi) \ln \left(\underline{h}^{*}+\underline{h}\right) .
$$

By the same token, $\underline{h}^{*}$ is also indifferent between being married and single, that is

$$
\ln (1-\theta(\underline{h}))+(1+\gamma n \psi) \ln \left(\underline{h}^{*}+\underline{h}\right)=\gamma n \psi \ln h_{1}+\ln \underline{h}^{*} .
$$


Putting these two conditions together, we see that the marriage viability condition (9) must be satisfied with equality at $h=\underline{h}$ and $h^{*}=\underline{h}^{*}$. But this implies that it is satisfied strictly for any $h<\underline{h}$ and $h^{*}=\underline{h}^{*}$. Therefore, a woman with human capital $h<\underline{h}$ can underbid $\underline{h}$ to marry $\underline{h}^{*}$ and give him a positive surplus, meaning that condition (iii) in Definition 2 must be violated. Hence, it cannot be that $\underline{h}>h_{\min }$, implying that if $\underline{h}^{*}>h_{\min }$ the equilibrium must be SATC.

Q.E.D.

\subsection{Proof of Proposition 3}

We construct a function $\theta(h)$ to match all three equilibrium conditions. Let us start with condition (iii). Since all women are married, their reservation utility is given by

$$
V(h)=\ln \theta(h)+(1+\gamma n \psi)\left(\ln A+\ln \left(h+h^{*}(h)\right)\right)+\pi_{\beta} .
$$

By marrying another man with human capital $h^{*}$ and get a fraction $\theta$ of consumption, their utility would be given by (7). Therefore, the consumption share that would make them indifferent between their marriage and this alternative marriage is given by

$$
\ln \hat{\theta}\left(h, h^{*}\right)=\ln \theta(h)+(1+\gamma n \psi)\left(\ln \left(h+h^{*}(h)\right)-\ln \left(h+h^{*}\right)\right) .
$$

The new husband utility is now

$$
U_{\beta}^{*}\left(h, h^{*}, \hat{\theta}\left(h, h^{*}\right)\right)=\ln \left(1-\hat{\theta}\left(h, h^{*}\right)\right)+(1+\gamma n \psi)\left(\ln A+\ln \left(h+h^{*}\right)\right)+\pi_{\beta} .
$$

It must not exceed the utility he had in his assigned marriage

$$
V^{*}\left(h^{*}\right)=\ln \left(1-\theta\left(h^{*-1}\left(h^{*}\right)\right)\right)+(1+\gamma n \psi)\left(\ln A+\ln \left(h^{*-1}\left(h^{*}\right)+h^{*}\right)\right)+\pi_{\beta} .
$$

Using (42) to eliminate $\hat{\theta}\left(h, h^{*}\right)$, and rearranging, we see that the condition $U_{\beta}^{*}\left(h, h^{*}, \hat{\theta}\left(h, h^{*}\right)\right) \leq V^{*}\left(h^{*}\right)$ is equivalent to

$$
\left(h+h^{*}\right)^{1+\gamma n \psi} \leq \theta(h)\left(h+h^{*}(h)\right)^{1+\gamma n \psi}+\left(1-\theta\left(h^{*-1}\left(h^{*}\right)\right)\right)\left(h^{*-1}\left(h^{*}\right)+h^{*}\right)^{1+\gamma n \psi},
$$


and this will hold with equality for $h^{*}=h^{*}(h)$.

In our candidate equilibrium, we have $h^{*}(h)=h$. The preceding formula can simply be rewritten as

$$
\left(h+h^{*}\right)^{1+\gamma n \psi} \leq \theta(h)(2 h)^{1+\gamma n \psi}+\left(1-\theta\left(h^{*}\right)\right)\left(2 h^{*}\right)^{1+\gamma n \psi} .
$$

Suppose now that we have $\theta(h)=\frac{1}{2}\left(1+\lambda h^{-(1+\gamma n \psi)}\right)$, this boils down to

$$
\left(\frac{h+h^{*}}{2}\right)^{1+\gamma n \psi} \leq \frac{h^{1+\gamma n \psi}+h^{* 1+\gamma n \psi}}{2},
$$

which is true by convexity.

Let us now check condition (i), i.e. that women are better-off married than single. Comparing (41) and (5), we see that the condition $V(h) \geq \bar{U}_{\beta}(h)$ is equivalent to

$$
\theta(h) \geq e^{k} 2^{-(1+\gamma n \psi)}
$$

If $\lambda \geq 0$ then $\theta^{\prime}(h) \leq 0$, so that all women are better-off than being single provided this inequality holds for $h=h_{\max }$, that is

$$
\lambda \geq\left(e^{k} 2^{-\gamma n \psi}-1\right) h_{\max }^{1+\gamma n \psi} .
$$

If $\lambda \leq 0$ then $\theta^{\prime}(h)>0$ and the condition is satisfied provided the inequality holds for $h=h_{\min }$, that is

$$
\lambda>\left(e^{k} 2^{-\gamma n \psi}-1\right) h_{\min }^{1+\gamma n \psi} .
$$

We see that either $e^{k} 2^{-\gamma n \psi}-1 \geq 0$ and $\lambda$ cannot be negative, so that (45) prevails, or $e^{k} 2^{-\gamma n \psi}-1<0$ and then all positive values of $\lambda$ satisfy (45), so that we only need (46). Putting these things together, we see that the values of $\lambda$ which make all women better-off than being single are those such that

$$
\lambda \geq \max \left(\left(e^{k} 2^{-\gamma n \psi}-1\right) h_{\min }^{1+\gamma n \psi},\left(e^{k} 2^{-\gamma n \psi}-1\right) h_{\max }^{1+\gamma n \psi}\right) .
$$

Turning now to condition (ii), using (43) and (1), and the fact that $h^{*-1}\left(h^{*}\right)=h^{*}$, the condition $V^{*}\left(h^{*}\right) \geq \bar{U}_{\beta}^{*}\left(h^{*}\right)$ is equivalent to

$$
1-\theta\left(h^{*}\right) \geq 2^{-(1+\gamma n \psi)} h_{1}^{\gamma n \psi} h^{*-\gamma n \psi} .
$$


If $\lambda \geq 0$ then the LHS goes up with $h^{*}$; since the RHS falls with $h^{*}$, then for this to hold for all $h^{*}$ it must hold for $h^{*}=h_{\min }$. We get the condition that

$$
\lambda \leq\left(1-2^{-\gamma n \psi} h_{1}^{\gamma n \psi} h_{\min }^{-\gamma n \psi}\right) h_{\min }^{1+\gamma n \psi} .
$$

Note that the RHS to this inequality is always positive.

If $\lambda<0$ then the LHS of (47) is always greater than 0.5 , and therefore always exceeds the RHS since $h^{*}>h_{1}$.

Summarizing all these findings, we see that there exist values of $\lambda$ which satisfy (i) and (ii) if and only if (16) holds. If (i) and (ii) hold for some $\lambda$ :

-either $e^{k} 2^{-\gamma n \psi}-1<0$; in this case (16) always holds, and we have seen that all negative values of $\lambda$ which satisfy (46) and all positive ones which satisfy (48) are eligible.

-or $e^{k} 2^{-\gamma n \psi}-1 \geq 0$, in which case the eligible values of $\lambda$ satisfy both (45) (implying they are positive) and (48). This set is non empty iff

$$
\left(1-2^{-\gamma n \psi} h_{1}^{\gamma n \psi} h_{\min }^{-\gamma n \psi}\right) h_{\min }^{1+\gamma n \psi} \geq\left(e^{k} 2^{-\gamma n \psi}-1\right) h_{\max }^{1+\gamma n \psi}
$$

which is equivalent to (16).

In both cases, the set of eligible values of $\lambda$ is described by condition (17).

Q.E.D.

\subsection{Proof of Proposition 4}

First, we prove that no Victorian equilibrium exists if (16) is violated. In the proof of Proposition 4, we have seen that for the equilibrium condition (??) to hold, it must be that (44) holds. We also know that (44) holds with equality at $h^{*}=h^{*}(h)$. Thus $h^{*}(h)$ must be a local extremum of the RHS of (44) minus its LHS, as a function of $h^{*}$. Locally, this means that:

$$
\begin{aligned}
& (1+\gamma n \psi)\left(h+h^{*}(h)\right)^{\gamma n \psi} \\
= & (1-\theta(h))(1+\gamma n \psi)\left(h+h^{*}(h)\right)^{\gamma n \psi} \times\left(1+h^{* \prime}(h)^{-1}\right) \\
& -\left(h+h^{*}(h)\right)^{1+\gamma n \psi} \frac{\theta^{\prime}(h)}{h^{* \prime}(h)} .
\end{aligned}
$$


In a Victorian equilibrium $h^{*}(h)=h$, and this simplifies to

$$
\theta^{\prime}(h)=\frac{1+\gamma n \psi}{2 h}(1-2 \theta(h)) .
$$

The solution to this differential equation is the one used in Prop. 3: $\theta(h)=\frac{1}{2}\left(1+\lambda h^{-(1+\gamma n \psi)}\right)$. Using the same steps as in the proof of Prop. 3, it is easy to see that for (i) and (ii) to hold in Definition 2, it must be that the integration constant $\lambda$ satisfies (17). But no such $\lambda$ exists if (16) is violated. Thus, a Victorian equilibrium cannot exist. Q.E.D.

\subsection{Proof of Proposition 5}

A. Constructing the assignment for the SATC equilibrium

We now show that an SATC equilibrium can be constructed. For this, we look for a pair $\left(\underline{h}^{*}, \bar{h}\right)$ such that $\underline{h}^{*}>h_{\min }, \bar{h}<h_{\max }$, and the assignment given by

$$
h^{*}(h)=F^{-1}\left(F(h)+F\left(\underline{h}^{*}\right)\right)
$$

is an equilibrium one. Clearly, given $\bar{h}$, if we choose

$$
\underline{h}^{*}=F^{-1}(1-F(\bar{h}))=\underline{h}^{*}(\hat{h}),
$$

the candidate assignment will map $S=\left[h_{\min }, \bar{h}\right]$ to $S^{*}=\left[\underline{h}^{*}, h_{\max }\right]$ and satisfy (11). Therefore, it is indeed an assignment:

- We have proved that given any $\bar{h}$, the value of $\underline{h}^{*}$ given by (51) and the $h^{*}()$ function defined by (50) are an assignment.

\section{B. Checking that married people cannot underbid one another}

Next, let us assume that the sharing function $\theta(h)$ satisfies $(20)$. We show that (iii) in Definition 2 holds for $h \in S$ and $h^{*} \in S^{*}$. As shown in the proof 
of Proposition 4, this is equivalent to (44). Substituting (20), we get that this is equivalent to

$$
\left(h+h^{*}\right)^{1+\gamma n \psi} \leq\left(h^{*-1}\left(h^{*}\right)+h^{*}\right)^{1+\gamma n \psi}+(1+\gamma n \psi) \int_{h^{*-1}\left(h^{*}\right)}^{h}\left(z+h^{*}(z)\right)^{\gamma n \psi} d z,
$$

for all $h, h^{*} \in S \times S^{*}$. Again, equality holds for $h^{*}=h^{*}(h)$. Furthermore, the derivative of the RHS of (52) with respect to $h^{*}$ is $(1+\gamma n \psi)\left(h^{*-1}\left(h^{*}\right)+h^{*}\right)^{\gamma n \psi}$, while the derivative of the LHS is $(1+\gamma n \psi)\left(h+h^{*}\right)^{\gamma n \psi}$. Given that $h^{*}(h)$ is increasing, the former is clearly larger than the latter for $h^{*}>h^{*}(h)$, and smaller for $h^{*}<h^{*}(h)$. Consequently, the difference between the RHS and the LHS reaches it minimum at $h^{*}=h^{*}(h)$; hence (52) holds.

- We have proved that if $\theta(h)$ satisfies (20), then condition (iii) holds for $\left(h, h^{*}\right) \in S \times S^{*}$.

C. Deriving the value-matching conditions at the frontier of $S$ and $S^{*}$

Next, we show that there exist values for $\mu, \bar{h}$ and $\underline{h}^{*}$ such that, in addition to (51), the two following conditions hold:

$$
\begin{gathered}
\bar{U}_{\alpha}(\bar{h})=U_{\beta}\left(\bar{h}, h_{\max }, \theta(\bar{h})\right) ; \\
\bar{U}_{\beta}^{*}\left(\underline{h}^{*}\right)=U_{\beta}^{*}\left(h_{\min }, \underline{h}^{*}, \theta\left(h_{\min }\right) .\right.
\end{gathered}
$$

These two conditions mean that the reservation utilities $V()$ and $V^{*}()$ do not jump as one crosses the boundaries of $S$ and $S^{*}$. Otherwise, the equilibrium conditions would be violated. Suppose, for example, that a woman such that $h$ is marginally higher than $\bar{h}$ has a utility higher than $U_{\beta}\left(\bar{h}, h_{\max }, \theta(\bar{h})\right)$ by a discrete amount. Then, since the $\theta()$ function is continuous over $S$, women with $h$ below $\bar{h}$ but arbitrarily close to it would be better-off being single, and condition (i) in Definition 2 would be violated. Suppose now that a woman with $h$ marginally higher than $\bar{h}$ has a utility lower than $U_{\beta}\left(\bar{h}, h_{\max }, \theta(\bar{h})\right)$ by a discrete amount. Then $\hat{\theta}\left(h, h_{\max }\right)<\theta(\bar{h}):$ since these women are arbitrarily close to $\bar{h}$, but have a discretely lower utility than the 
married women with $\bar{h}$, they can reach that same utility by marrying a man with $h_{\max }$ and get a lower fraction of the surplus. But the $h_{\max }$ man would then be better-off and this would violate condition (iii). Therefore, (53) must hold. A similar reasoning applies to (54). Using (4) and (7), we see that (53) is equivalent to

$$
\ln \theta(\bar{h})=k+(1+\gamma n \psi) \ln \bar{h}-(1+\gamma n \psi) \ln \left(\bar{h}+h_{\max }\right) .
$$

Substituting (20), we see that this is equivalent to

$$
\mu=e^{k} \bar{h}^{1+\gamma n \psi}-(1+\gamma n \psi) \int_{h_{\min }}^{\bar{h}}\left(z+h^{*}(z)\right)^{\gamma n \psi} d z=\mu_{H}(\bar{h})
$$

Similarly, we can substitute (1) and (8) into (54) and get

$$
\ln \left(1-\theta\left(h_{\min }\right)\right)=-\gamma n \psi \ln A-\pi_{\beta}+\ln \underline{h}^{*}-(1+\gamma n \psi) \ln \left(h_{\min }+\underline{h}^{*}\right),
$$

or equivalently, given (20),

$$
\mu=\left(h_{\min }+\underline{h}^{*}\right)^{1+\gamma n \psi}-h_{1}^{\gamma n \psi} \underline{h}^{*}=\mu_{L}(\bar{h})
$$

Equations (55) and (56) define a 2x2 system in $\bar{h}$ and $\mu$, where $\underline{h}^{*}$ is implicitly treated as a function of $\bar{h}$ defined by (51).

- We have proved that $\mu$ and $\bar{h}$ must satisfy (55) and (56) in equilibrium.

D. Showing that there is a solution, for $\mu, \bar{h}, \underline{h}^{*}$ which satisfies the valuematching conditions as well as condition (iii) in Definition 2 for singles

To prove that it has a solution, we use the intermediate value theorem. First, we show that $\mu_{H}\left(h_{\max }\right)>\mu_{L}\left(h_{\max }\right)$. In such a case, one has $h^{*}(h)=h$. Therefore, $\mu_{H}\left(h_{\max }\right)=e^{k} h_{\max }^{1+\gamma n \psi}-2^{\gamma n \psi}\left(h_{\max }^{1+\gamma n \psi}-h_{\min }^{1+\gamma n \psi}\right)$, and $\mu_{L}\left(h_{\max }\right)=$ $2^{1+\gamma n \psi} h_{\min }^{1+\gamma n \psi}-h_{1}^{\gamma n \psi} h_{\min }$. Clearly, the condition $e^{k} h_{\max }^{1+\gamma n \psi}-2^{\gamma n \psi}\left(h_{\max }^{1+\gamma n \psi}-h_{\min }^{1+\gamma n \psi}\right)>$ $2^{1+\gamma n \psi} h_{\min }^{1+\gamma n \psi}-h_{1}^{\gamma n \psi} h_{\min }$ is equivalent to (16) being violated, which is true by assumption. 
Next, let $\hat{h}$ be the minimum possible value of $\bar{h}$ such that condition (iii) in definition 2 holds for $h>\bar{h}$ and $h^{*}<\underline{h}^{*}$. The threshold $\hat{h}$ is such that a marriage between the least skilled single woman and the most skilled single man is barely viable, i.e.

$$
\left(\hat{h}+\underline{h}^{*}(\hat{h})\right)^{1+\gamma n \psi}=h_{1}^{\gamma n \psi} \underline{h}^{*}(\hat{h})+e^{k} \hat{h}^{1+\gamma n \psi} .
$$

Since $(51)$ implies that $\underline{h}^{* \prime}()<0$, while $(57)$ states that $\left(\underline{h}^{*}(\hat{h}), \hat{h}\right)$ lies on the upward sloping marriage viability frontier, there exists a unique $\hat{h}$ that satisfies (57). Furthermore, since (15) holds, this pair must satisfy $\underline{h}^{*}<\bar{h}$.

We show that $\mu_{H}(\hat{h})<\mu_{L}(\hat{h})$. Substituting (57) into (55), we see that this is equivalent to

$$
\left(\hat{h}+\underline{h}^{*}(\hat{h})\right)^{1+\gamma n \psi}-(1+\gamma n \psi) \int_{h_{\min }}^{\hat{h}}\left(z+h^{*}(z)\right)^{\gamma n \psi} d z<\left(h_{\min }+\underline{h}^{*}(\hat{h})\right)^{1+\gamma n \psi} .
$$

This inequality always holds. ${ }^{32}$ Thus, by the intermediate value theorem, there exists a solution to (55)-(56) such that $\hat{h}<\bar{h}<h_{\max }$.

- We have proved that there exists a pair $(\mu, \bar{h})$ such that $(55)-(56)$ hold and that condition (iii) in Definition 2 holds for $\left(h, h^{*}\right) \in\left[h_{\min }, h_{\max }\right]-$ $S \times\left[h_{\min }, h_{\max }\right]-S^{*}$.

E. Checking that the constructed solution satisfies (iii) for a single woman and a married man

Another requirement is that condition (iii) hold for $h>\bar{h}$ and $h^{*} \in S^{*}$. Using (4) and (7), we must have

$$
\ln \hat{\theta}\left(h, h^{*}\right)=(1+\gamma n \psi)\left(\ln h-\ln \left(h+h^{*}\right)\right)+k .
$$

Using (8), we see that (14) is equivalent to

\footnotetext{
${ }^{32}$ Denoting the LHS by $\phi\left(\hat{h}, \underline{h}^{*}(\hat{h})\right)$, and its RHS by $R$, it can be checked that $\phi\left(h_{\min }, \underline{h}^{*}(\hat{h})\right)=R$ and that $\phi_{1}^{\prime}<0$.
} 


$$
\begin{aligned}
& \ln \left(1-\hat{\theta}\left(h, h^{*}\right)\right)+(1+\gamma n \psi)\left(\ln A+\ln \left(h+h^{*}\right)\right)+\pi_{\beta} \\
\leq & V^{*}\left(h^{*}\right) \\
= & \ln \left(1-\theta\left(h^{*-1}\left(h^{*}\right)\right)\right)+(1+\gamma n \psi)\left(\ln A+\ln \left(h^{*}+h^{*-1}\left(h^{*}\right)\right)\right)+\pi_{\beta}(59)
\end{aligned}
$$

Substituting (58) and (20), we see that this is equivalent to

$$
\begin{aligned}
\mu \leq & \left(h^{*}+h^{*-1}\left(h^{*}\right)\right)^{1+\gamma n \psi}-(1+\gamma n \psi) \int_{h_{\min }}^{h^{*-1}\left(h^{*}\right)}\left(z+h^{*}(z)\right)^{\gamma n \psi} d z(60) \\
& +e^{k} h^{1+\gamma n \psi}-\left(h+h^{*}\right)^{1+\gamma n \psi} \\
= & \phi\left(h, h^{*}\right) .
\end{aligned}
$$

Since $(55)$ holds by construction, we have that $\phi\left(\bar{h}, h_{\max }\right)=\mu$. Furthermore,

$$
\frac{\partial \phi}{\partial h}=(1+\gamma n \psi)\left[e^{k} h^{\gamma n \psi}-\left(h+h^{*}\right)^{\gamma n \psi}\right] .
$$

Therefore, $\frac{\partial \phi}{\partial h} \geq 0$ if and only if $e^{k} \geq\left(1+\frac{h^{*}}{h}\right)^{\gamma n \psi}$.

Let us assume that

$$
e^{k} \geq\left(1+\frac{h_{\max }}{\bar{h}}\right)^{\gamma n \psi}
$$

. It must then be that $e^{k} \geq\left(1+\frac{h^{*}}{h}\right)^{\gamma n \psi}$ for all $h^{*} \in S^{*}$ and for all $h \geq \bar{h}$. Consequently, $\phi\left(h, h^{*}\right) \geq \phi\left(\bar{h}, h^{*}\right)$. But we must have $\phi\left(\bar{h}, h^{*}\right) \geq \mu$ : Since $\bar{h} \in S$, (14) is equivalent to (44) for $\left(\bar{h}, h^{*}\right)$, and we already know that (44) holds. Therefore, $\phi\left(h, h^{*}\right) \geq \mu$. Hence, condition (61) is sufficient for (iii) to hold for $h^{*} \in S^{*}$ and $h>\bar{h}$. Furthermore, if condition (16) holds with equality, we have that $e^{k}>2^{\gamma n \psi}$, and in this limit case the solution to (55)(56) is $\bar{h}=h_{\max }$. (61) then strictly holds. By continuity, if $h_{\max }$ is such that (16) is not violated by too much, i.e. $B$ in (18) is not too large, then (61) will hold.

- We have proved that we can choose $B$ such that the values of $\mu$ and $\bar{h}$ constructed in D are such that condition (iii) in Definition 2 holds for $\left(h, h^{*}\right) \in\left[h_{\min }, h_{\max }\right]-S \times S^{*}$. 


\section{F. Checking that the constructed solution satisfies (i)}

The condition that married women are better-off than if they were single can be written

$$
\ln \theta(h)+(1+\gamma n \psi) \ln \left(h+h^{*}(h)\right) \geq(1+\gamma n \psi) \ln h+k, \forall h \leq h^{*}
$$

or equivalently using the formula for $\theta(h)$ :

$$
\mu \geq e^{k} h^{1+\gamma n \psi}-(1+\gamma n \psi) \int_{h_{\min }}^{h}\left(z+h^{*}(z)\right)^{\gamma n \psi} d z=\phi(h)
$$

Again, (55) implies that it holds with equality at $h=\bar{h}$. Furthermore, $\phi^{\prime}(h)=(1+\gamma n \psi)\left(e^{k} h^{\gamma n \psi}-\left(h+h^{*}(h)\right)^{\gamma n \psi}\right)$. We have $\phi^{\prime}(h)>0$ if and only if $h^{*}(h) / h<e^{\frac{k}{\gamma n \psi}}-1$. This is again true in the limit case where (16) holds with equality, since we then have $h^{*}(h)=h$ and $e^{\frac{k}{\gamma n \psi}}>2$. Therefore, in this limit equilibrium we have $\phi(h)<\phi(\bar{h})$. By continuity, this remains true if $(15)$ is not violated by too much. Then (63) holds, and condition (i) in Definition 2 is satisfied.

- We have proved that we can choose $B$ such that, in addition to the properties spelled out above, condition (i) in Definition 2 holds.

G. Checking that the constructed solution satisfies (iii) for a single man and a married woman

We now prove that (iii) holds when $h^{*}<\underline{h}^{*}$. Here it is more convenient to use the alternative formulation defined in footnote 21. Using (1) and (8) allows us to compute $\hat{\theta}^{*}\left(h, h^{*}\right)$ :

$$
\hat{\theta}^{*}\left(h, h^{*}\right)=1-\frac{h_{1}^{\gamma n \psi} h^{*}}{\left(h+h^{*}\right)^{1+\gamma n \psi}} .
$$

Comparing (7) for $\theta=\hat{\theta}^{*}\left(h, h^{*}\right)$ and for $\theta=\theta(h)$ and $h^{*}(h)$ instead of $h^{*}$, , we see that the condition in footnote 21 holds if and only if

$$
\hat{\theta}^{*}\left(h, h^{*}\right) \leq \theta(h) \frac{\left(h+h^{*}(h)\right)^{1+\gamma n \psi}}{\left(h+h^{*}\right)^{1+\gamma n \psi}} .
$$


Substituting (20) and (64) we get the following condition

$$
\left(h+h^{*}\right)^{1+\gamma n \psi}-h_{1}^{\gamma n \psi} h^{*} \leq \mu+(1+\gamma n \psi) \int_{h_{\min }}^{h}\left(z+h^{*}(z)\right)^{\gamma n \psi} d z .
$$

Note that this holds with equality for $h=h_{\min }$ and $h^{*}=\underline{h}^{*}$, by virtue of (56). Next, note that the LHS is an increasing function of $h^{*}$. Therefore, (65) holds for all $h^{*}<\underline{h}^{*}$ if and only if it holds for $h^{*}=\underline{h}^{*}$. Next, note that the derivative of the RHS with respect to $h$ is $(1+\gamma n \psi)\left(h+h^{*}(h)\right)^{\gamma n \psi}$, while the derivative of the LHS at $h^{*}=\underline{h}^{*}$ is $(1+\gamma n \psi)\left(h+\underline{h}^{*}\right)^{\gamma n \psi}$. The former is clearly larger than the latter since $h^{*}(h) \geq \underline{h}^{*}$. Therefore, the difference between the RHS of (65) and its LHS at $h^{*}=\underline{h}^{*}$ is an increasing function of $h$. Since (65) holds with equality for $h=h_{\min }$ and $h^{*}=\underline{h}^{*}$, it also holds for any $h \geq h_{\min }$ and $h^{*}=\underline{h}^{*}$. As we have already seen, that in turn implies that it holds for any $h \geq h_{\min }$ and $h^{*}<\underline{h}^{*}$. This completes the proof that (iii) holds for single men underbidders.

- We have proved that the values of $\mu$ and $\bar{h}$ constructed in D are such that condition (iii) in Definition 2 holds for $\left(h, h^{*}\right) \in S \times\left[h_{\min }, h_{\max }\right]-$ $S^{*}$.

\section{H. Proof that (ii) holds for the constructed solution}

The last thing we have to check is that (ii) holds, that is, married men are better-off than if they were single. Denoting by $h$ the wife of a married man and by $h^{*}(h)$ this man, we see that this is equivalent to

$$
\ln A+\ln h^{*}(h) \leq \ln (1-\theta(h))+(1+\gamma n \psi)\left(\ln A+\ln \left(h+h^{*}(h)\right)\right)+\pi_{\beta} .
$$

Substituting in (20), we see that this is equivalent to

$$
\mu \leq\left(h+h^{*}(h)\right)^{1+\gamma n \psi}-h_{1}^{\gamma n \psi} h^{*}(h)-(1+\gamma n \psi) \int_{h_{\min }}^{h}\left(z+h^{*}(z)\right)^{\gamma n \psi} d z .
$$

Again, this holds with equality for $h=h_{\min }$, because of (56). Furthermore, the RHS's derivative with respect to $h$ is equal to $h^{* \prime}(h)\left[(1+\gamma n \psi)\left(h+h^{*}(h)\right)^{\gamma n \psi}-h_{1}^{\gamma n \psi}\right]$, 
which is clearly positive since $h^{*}()$ is increasing and $h+h^{*}(h)>h_{1}$. Therefore, the RHS of (66) is an increasing function of $h$ and is always greater for $h>h_{\min }$ than for $h=h_{\min }$, where it holds with equality. Hence (66) always holds:

- We have proved that the values of $\mu$ and $\bar{h}$ constructed in D are such that condition (ii) in Definition 2 holds.

This completes the proof of Proposition 5.

Q.E.D.

\subsection{Proof of Proposition 6}

The discussion in D. in the proof of proposition 5 implies that we can always pick an equilibrium such that locally, the RHS of (55) as a function of $\underline{h}^{*}$ is flatter than that of (56). It is then clear that a rise in $k$ shifts the RHS of (55) up, and has no effect on (56). Therefore, both $\underline{h}^{*}$ and $\mu$ go up, which proves claim (i). Similarly, a greater $h_{1}$ reduces the RHS of (56), with no effect on (55), so that $\underline{h}^{*}$ goes up again while $\mu$ falls. This proves claim (ii).

Finally, note that $h_{\max }$ does not enter in (56) and that for a uniform distribution, (55) is equivalent to

$$
\mu=e^{k}\left(h_{\max }-\delta\right)^{1+\gamma n \psi}-2^{\gamma n \psi}\left[\left(h_{\max }-\delta / 2\right)^{1+\gamma n \psi}-\left(h_{\min }+\delta / 2\right)^{1+\gamma n \psi}\right],
$$

where $\delta=\underline{h}^{*}-h_{\min }$, and $h^{*}(h)=h+\delta$. The constructed equilibrium is such that (61) holds. This also implies that the RHS of (67) is increasing in $h_{\max }$, holding $\underline{h}^{*}$ or equivalently $\delta$ constant. Consequently, a greater $h_{\max }$ raises the RHS of (55), so that the equilibrium values of $\mu$ and $\underline{h}^{*}$ go up. The proportion of married people is $1-\frac{\delta}{h_{\max }-h_{\min }}$, and it must go down. It falls iff $\frac{d \delta}{d h_{\max }}>\frac{\delta}{h_{\max }-h_{\min }}$, which is true if $\delta$ is small enough, which is true in the constructed equilibrium of Prop. 5.

Q.E.D. 


\subsection{Proof of Proposition 7}

Suppose we are at an optimum. Then output cannot increase by swapping two members between two couples. Consider two married women with human capital levels $h_{0}$ and $h_{2}$ such that $h_{0}<h_{2}$. Then the contribution of these couples to output is proportional two $\left(h_{0}+h^{*}\left(h_{0}\right)\right)^{\psi}+\left(h_{2}+h^{*}\left(h_{2}\right)\right)^{\psi}$. If they were to swap, their contribution to output would be proportional to $\left(h_{0}+h^{*}\left(h_{2}\right)\right)^{\psi}+\left(h_{2}+h^{*}\left(h_{0}\right)\right)^{\psi}$. Therefore, it must be that

$$
\left(h_{0}+h^{*}\left(h_{2}\right)\right)^{\psi}+\left(h_{2}+h^{*}\left(h_{0}\right)\right)^{\psi} \leq\left(h_{0}+h^{*}\left(h_{0}\right)\right)^{\psi}+\left(h_{2}+h^{*}\left(h_{2}\right)\right)^{\psi},
$$

or equivalently

$$
\left(h_{0}+h^{*}\left(h_{2}\right)\right)^{\psi}-\left(h_{0}+h^{*}\left(h_{0}\right)\right)^{\psi} \leq\left(h_{2}+h^{*}\left(h_{2}\right)\right)^{\psi}-\left(h_{2}+h^{*}\left(h_{0}\right)\right)^{\psi} .
$$

Let $g(x)=(x+a)^{\psi}-(x+b)^{\psi}$. We have $g^{\prime}(x)=\psi\left[(x+a)^{\psi-1}-(x+b)^{\psi-1}\right]$. Clearly, since $\psi<1, g^{\prime}(x)>0$ iff $a<b$ and $g^{\prime}(x)<0$ iff $a>b$. Consequently, since $h_{2}>h_{0}$, for (68) to hold we must have $h^{*}\left(h_{2}\right)<h^{*}\left(h_{0}\right)$. Therefore, the $h^{*}$ () function must be decreasing. This proves claim (iii).

Consider now a single woman with human capital $h_{2}$ and a married one with human capital $h_{0}$. Their contribution to output is proportional to

$$
\left(p_{\beta} \alpha+\left(1-p_{\beta}\right) \beta\right)\left(h_{0}+h^{*}\left(h_{0}\right)\right)^{\psi}+\left(p_{\alpha} \alpha+\left(1-p_{\alpha}\right) \beta\right) h_{2}^{\psi} .
$$

If they were to swap, their contribution to output would be equal to

$$
\left(p_{\beta} \alpha+\left(1-p_{\beta}\right) \beta\right)\left(h_{2}+h^{*}\left(h_{0}\right)\right)^{\psi}+\left(p_{\alpha} \alpha+\left(1-p_{\alpha}\right) \beta\right) h_{0}^{\psi} .
$$

The latter must not exceed the former, so that we need to have

$$
g\left(h_{2}\right) \leq g\left(h_{0}\right)
$$

with $g()$ now defined as $g(x)=\left(p_{\beta} \alpha+\left(1-p_{\beta}\right) \beta\right)\left(x+h^{*}\left(h_{0}\right)\right)^{\psi}-\left(p_{\alpha} \alpha+(1-\right.$ $\left.\left.p_{\alpha}\right) \beta\right) x^{\psi}$. 
Given that $\psi<1, \alpha>\beta$, and $p_{\alpha}>p_{\beta}$, it is clear that $g^{\prime}()<0$. Therefore, we must have $h_{2} \geq h_{0}$.

Finally, it is obvious that if a single beta man is richer than a married beta man, a swap between the two will increase total output.

Q.E.D.

\subsection{Proof of Proposition 8}

Proposition 6 implies that the solution must be such that women are married for $h<\bar{h}$ and single for $h>\bar{h}$, and that men are married for $h^{*}>\underline{h}^{*}$ and single for $h^{*}<\underline{h}^{*}$. Furthermore, the only decreasing assignment function which matches the availability constraint is clearly $h^{*}(h)=\eta(h)$. From there, it is straightforward that the optimum maximizes

$\max _{\bar{h}} \int_{h_{\min }}^{\bar{h}}\left(p_{\beta} \alpha+\left(1-p_{\beta}\right) \beta\right)\left(h+h^{*}(h)\right)^{\psi} f(h) d h+\int_{\bar{h}}^{h_{\max }}\left(p_{\alpha} \alpha+\left(1-p_{\alpha}\right) \beta\right) h^{\psi} f(h) d h$.

The derivative with respect to $\bar{h}$ has the same sign as $\left(\bar{h}+h^{*}(\bar{h})\right)^{\psi}-\kappa \bar{h}^{\psi}$, which we denote by $g(\bar{h})$. This quantity is decreasing with $\bar{h}$ because $\psi<$ $1, \kappa>1$ and $h^{* \prime}()<0$. Therefore, if $g\left(h_{\max }\right)>0, g(\bar{h})>0$ throughout and the optimum is $\bar{h}=h_{\max }$. This is case (i) in Proposition 8. The two other cases correspond to $g\left(h_{\min }\right)>0>g\left(h_{\max }\right)$ and $g\left(h_{\min }\right)<0$.

Q.E.D.

\subsection{Proof of Proposition 9}

First, note that a Victorian equilibrium among the alphas always exists. This is because the apha's marriage problem is identical to the beta's except that $k=0$ in this case: women marrying an alpha would access the same genetic material if they were single instead. Since Proposition 4 holds for $k=0$, such an equilibrium exists.

Next, assume that at date $t$, all alpha agents have a human capital level lower than $h_{\max , \alpha}^{L R}=\exp \left(\frac{v_{1}+\ln 2}{1-\psi}\right)$, and all beta agents have a human capital lower than $h_{\max , \beta}^{L R}=\exp \left(\frac{v_{1}+\ln 2-(1-\psi) \ln \frac{\alpha}{\beta}}{1-\psi}\right)$. 
Clearly, for generation $t+1$, the human capital level of an alpha cannot exceed that of the alpha children of a couple such that the man is alpha and has human capital $h_{\max , \alpha}^{L R}$. This can be written as:

$$
h \leq \ln 2+v_{1}+\psi \ln h_{\max , \alpha}^{L R} .
$$

By construction, the RHS is equal to $h_{\max , \alpha}^{L R}$. Therefore, all the alphas in generation $t+1$ have a human capital which cannot exceed $h_{\max , \alpha}^{L R}$. As for the betas of that generation, they cannot do better than the beta children of an alpha couple with human capital $h_{\max , \alpha}^{L R}$ :

$$
h \leq \ln 2+v_{1}+\psi \ln h_{\max , \alpha}^{L R}-\ln \left(\frac{\alpha}{\beta}\right)=h_{\max , \beta}^{L R}<h_{\max , \alpha}^{L R} .
$$

Therefore, the property that $h<h_{\max , \beta}^{L R}$ for all the betas and $h<h_{\max , \alpha}^{L R}$ for all the alphas will remain true across all generations, regardless of how the betas mate.

Assume that at date $t$, all agents have a human capital level larger than $h_{\min , \beta}^{L R}=\exp \left(\frac{v_{1}+\ln 2-\ln \frac{\alpha}{\beta}}{1-\psi}\right)$. In condition $(16), \omega\left(h_{\min }, h_{\max }\right)$ is an increasing function of $h_{\min }$ and a decreasing function of $h_{\max }$. By assumption, (16) holds for $h_{\min }=h_{\min , \beta}^{L R}$ and $h_{\max }=h_{\max , \beta}^{L R}$. By assumption, the distribution of the beta's human capital at $t$ is such that $h_{\min , \beta}^{L R} \leq h_{\min , t} \leq h_{\max , t} \leq h_{\max , \beta}^{L R}$. Therefore, (16) holds. Hence, there exists a marriage market equilibrium at $t$ which is Victorian for the betas. Furthermore, in generation $t+1$, the lowest human capital level of a beta cannot exceed that of a beta offspring of a beta couple with human capital $h_{\min , \beta}^{L R}$ :

$$
h \geq \ln 2+v_{1}+\psi \ln h_{\min , \beta}^{L R}-\ln \left(\frac{\alpha}{\beta}\right)=h_{\min , \beta}^{L R} .
$$

Therefore, the property that $h>h_{\min , \beta}^{L R}$ still holds among the betas (and, a fortiori, among the alphas ${ }^{33}$ ) of generation $t+1$, implying that a Victorian equilibrium also exists for them. By induction, $h>h_{\min , \beta}^{L R}$ for all generations

\footnotetext{
${ }^{33}$ The alphas will, from date $t=1$ on, have a human capital strictly above $h_{\min , \alpha}^{L R}=$ $\exp \left(\frac{v_{1}+\ln 2-\psi \ln \frac{\alpha}{\beta}}{1-\psi}\right)>h_{\min , \beta}^{L R}$
} 
and a Victorian equilibrium exists at all dates. This proves claim (i) in Proposition 9.

Claim (ii) derives straightforwardly from the fact that all agents marry, so that a fraction $\rho_{t}$ of children have alpha fathers.

Claim (iii) derives straightforwardly from aggregating log human capital among all offsprings of types alpha and beta.

Q.E.D. 
Figure 1 - The marriage frontier

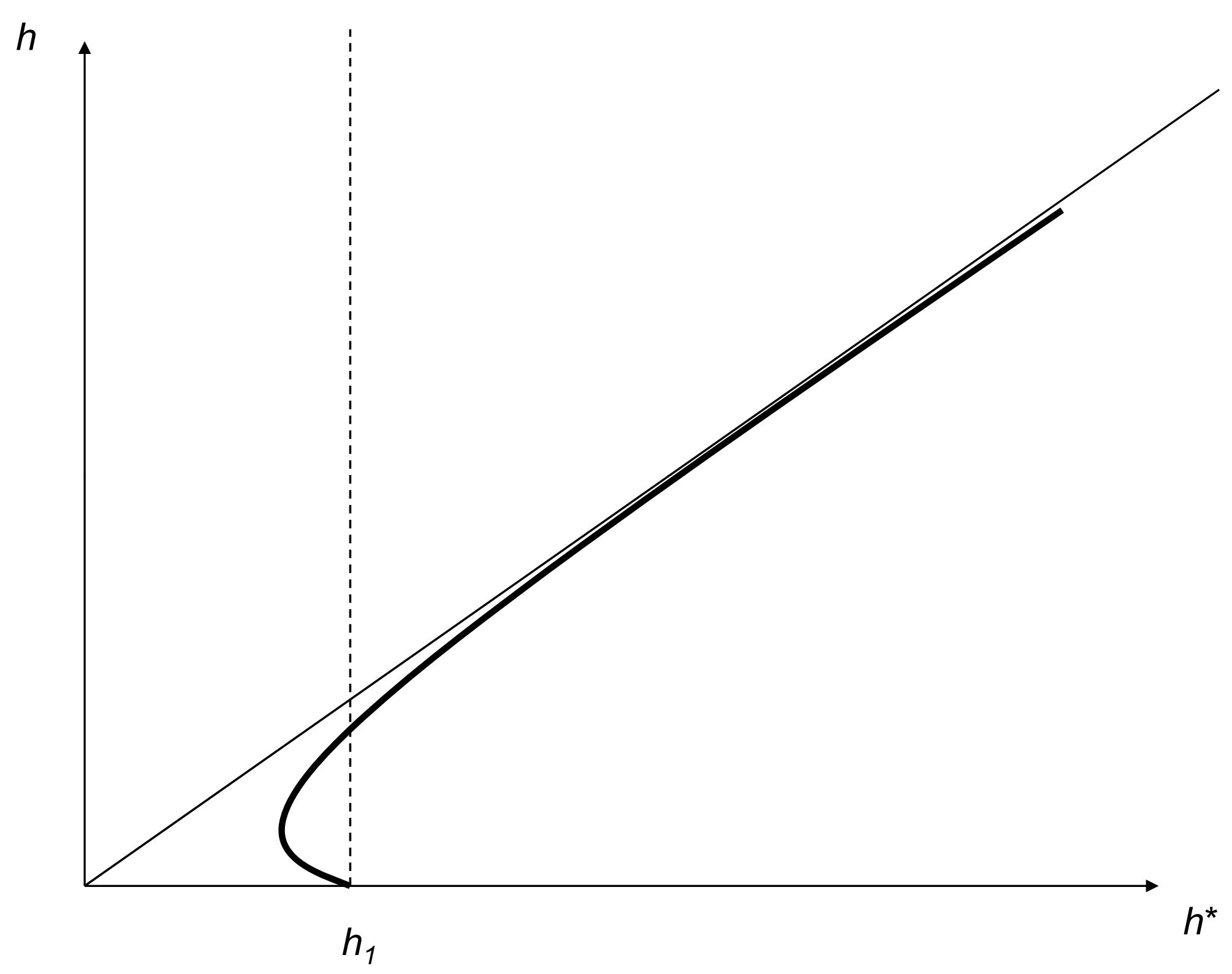


Figure 2 - The child improvement frontier

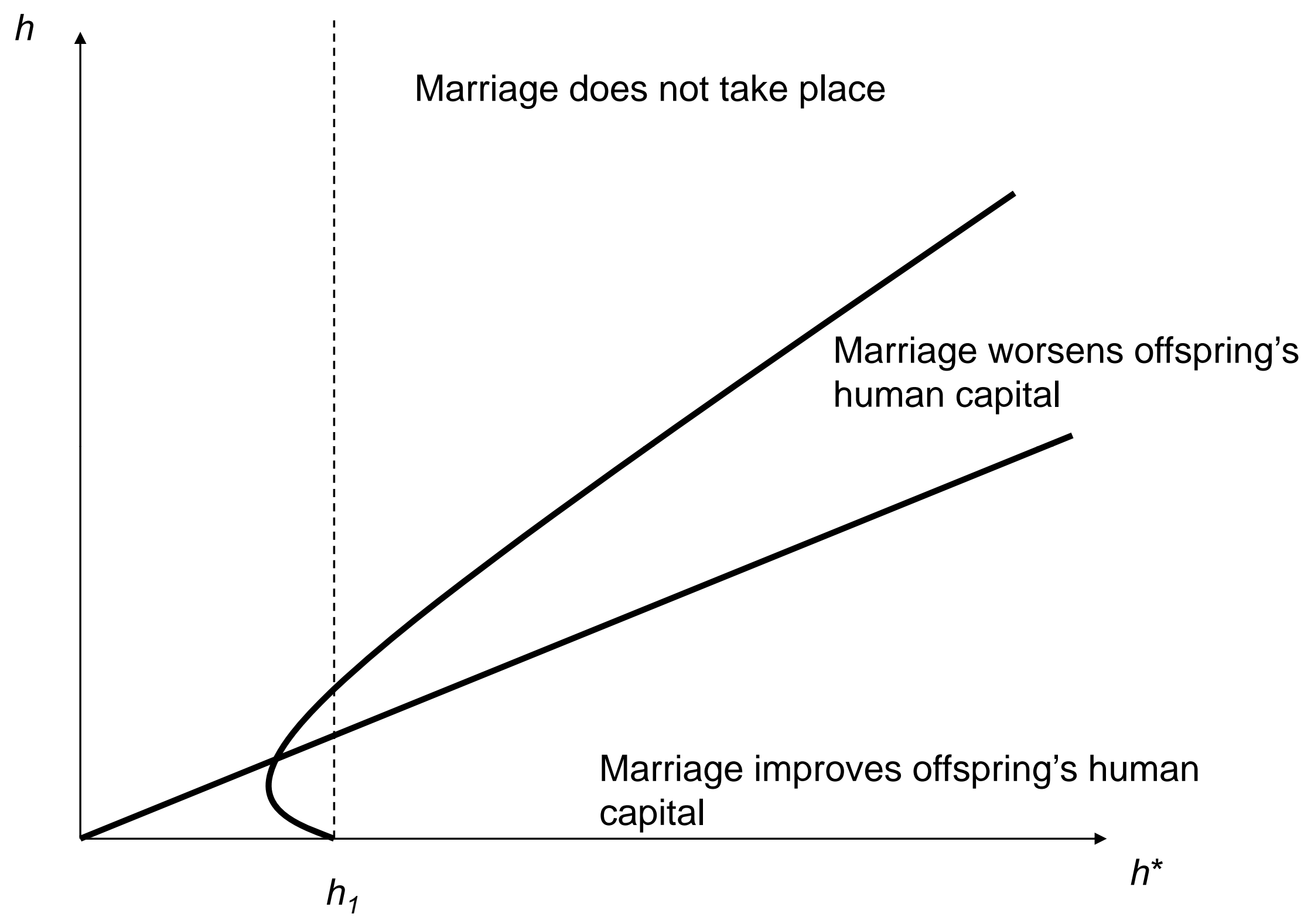


Figure 3 - The output maximizing matching pattern

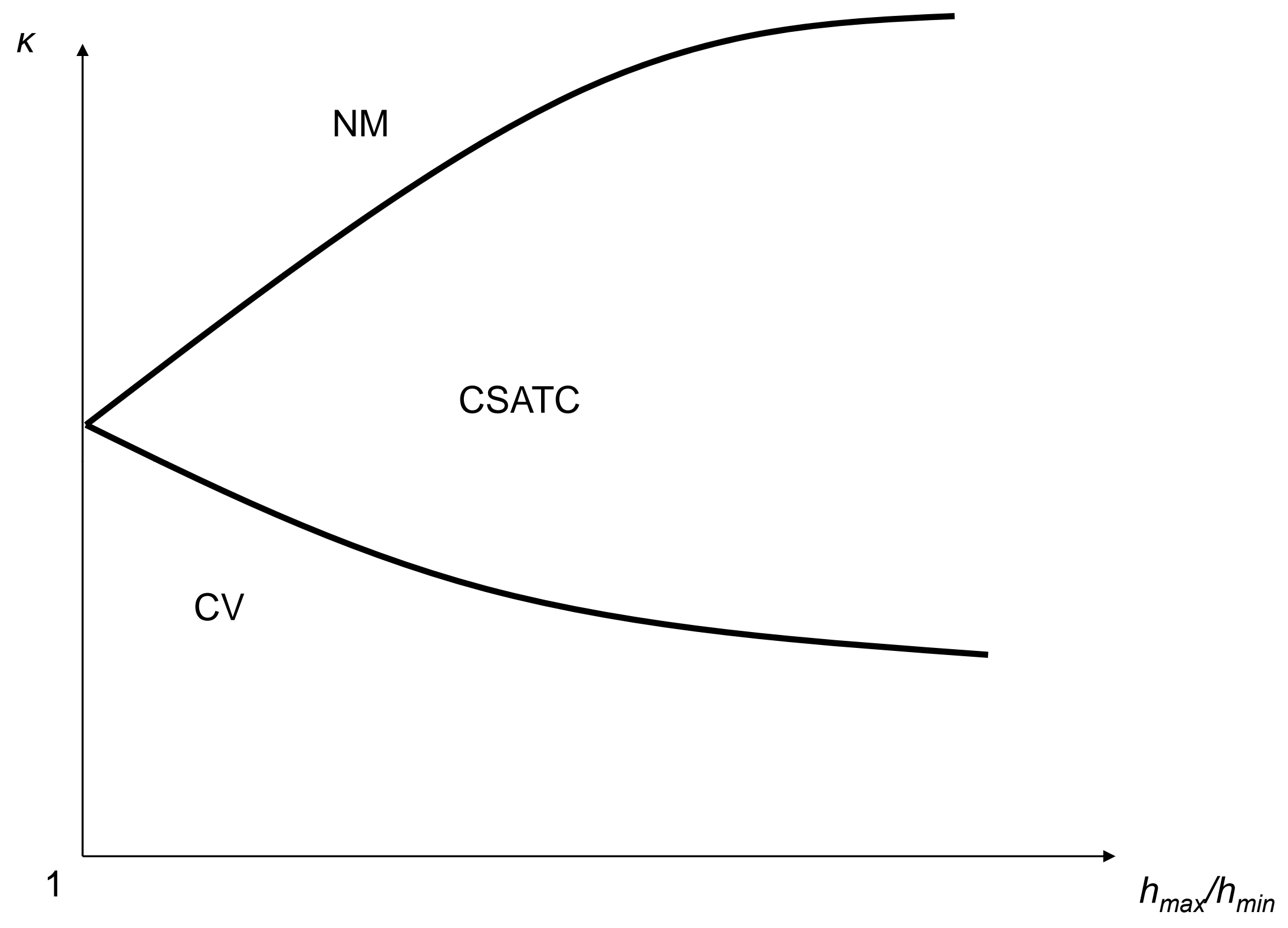

